\title{
Counterparty Credit Risk in Interest Rate Swaps during Times of Market Stress
}

\author{
Antulio N. Bomfim*
}

Federal Reserve Board

First Draft: September 27, 2002

This Draft: December 17, 2002

\begin{abstract}
This paper examines whether empirical and theoretical results suggesting a relatively small role for counterparty credit risk in the determination of interest rate swap rates hold during periods of stress in the financial markets, such as the chain of events that followed the Russian default crisis of 1998 . The analysis sheds light on the robustness of netting and credit enhancement mechanisms, which are common in interest rate swaps, to widespread turmoil in the financial markets.
\end{abstract}

\section{JEL Classification: G12, G13}

Keywords: convexity adjustment, futures and forward rates, affine models

*Board of Governors of the Federal Reserve System, Washington, DC 20551; E-mail: abomfim@frb.gov; Fax: (202) 452-2301, Tel.: (202) 736-5619. I am grateful to Jeff Dewynne and Pat White for helpful comments, to Emily Cauble and Joseph Rosenberg for excellent research assistance, and to seminar participants at the Federal Reserve Board for their insights. The opinions expressed in this paper are not necessarily shared by the Board of Governors of the Federal Reserve System or any other members of its staff. 


\section{Introduction}

Spreads of rates on interest rate swaps over comparable U.S. Treasury yields widened dramatically during the acute financial market turmoil that followed the Russian default crisis of 1998 (Figure 1). While a significant portion of that widening in swap spreads likely reflected increased concerns about credit risk in general and greater demand by investors for the safety and liquidity of Treasury securities - corporate bond and LIBOR spreads over Treasuries had also moved substantially higher - it is conceivable that swap spreads were also affected by market participants' worries about counterparty credit risk in swaps. This paper examines a well-known no-arbitrage relationship between interest rate swaps and eurodollar futures contracts to take a novel look at this issue. In particular, I examine whether the spread between swap rates quoted by dealers and "synthetic" swap rates implied by the futures marketwhere counterparty credit risk is virtually absent-provided any indication that swap rates were signaling heightened concerns about counterparty risk in the swaps market at that time.

Understanding the potential role that concerns about counterparty credit risk play in the pricing of interest rate swaps during times of financial market stress is important for at least two reasons. First, while a vast academic literature has studied the issue both from a theoretical and an empirical perspective, existing studies have not assessed the robustness of their findings to episodes of turmoil in the financial markets. Second, the interest swap market has been increasingly taking on a benchmark role in the broader fixedincome market that had previously virtually been the exclusive domain of U.S. Treasury debt securities. Given its greater prominence for the financial markets as a whole, the question of assessing the ability of the swaps market to continue to function without major impediments - such as heightened concerns about counterparty credit risk - when other (less liquid) markets are disrupted gains special significance for academics, market practitioners, 
and policymakers alike.

This paper is organized as follows. In Section 2, I provide some background on the institutional make-up of the interest rate swap market, as well as the theoretical underpinnings of swap valuation. Section 3 contains a review of the literature on counterparty credit risk in swaps, and, in Section 4, I discuss the construction of synthetic swap rates from futures rates, including a discussion of the modeling framework used to estimate the convexity differential between futures and forward rates. In Section 5, I describe how synthetic swap rates were constructed in practice. I conduct formal statistical comparisons between market and synthetic swap rates in Section

6 , examining the potential role of counterparty credit risk in the pricing of swaps in general and during times of market stress in particular. Section 7 includes an assessment of the robustness of the main results to different modeling assumptions in the derivation of the convexity adjustment, and, in Section 8, I discuss alternative interpretations of the findings. Section 9 contains an overall summary and the main conclusions.

\section{Interest Rate Swaps}

In its most common (vanilla) form, an interest rate swap is an agreement between two parties to exchange fixed and variable interest rate payments on a notional principal amount over a predetermined period ranging from one to thirty years. The notional amount itself is never exchanged. In the United States, the variable interest rate is typically six- or three-month LIBOR, and the fixed interest rate, which is determined in the swaps market, is generally quoted as a spread to yields on recently auctioned Treasury securities of comparable maturity.

The overall credit quality of swap market participants is high, commonly rated $\mathrm{A}$ or above; those entities with credit ratings of $\mathrm{BBB}$ or lower are typically either rejected or required to adopt stricter credit enhancing mech- 
anisms, which are clauses in swap agreements that are intended to mitigate concerns about counterparty credit risk in swaps. Such mechanisms include (i) credit triggers clauses, which give the higher-quality counterparty the right to terminate the swap if its counterparty's credit rating falls below, say, BBB, (ii) the posting of collateral against the market value of the swap, and (iii) requirements to obtain insurance or guarantees from highly-rated third parties (Litzenberger, 1992).

Swaps are negotiated and traded in a large over-the-counter market that has grown spectacularly since its inception in the early 1980s. According to the Bank for International Settlements (2002), notional amounts outstanding in U.S. dollar-denominated swaps reached $\$ 19$ trillion at the end of 2001. Most swaps are entered with dealers, who then seek to limit their exposure to interest rate risk by entering into offsetting swaps with other counterparties. In addition to swap dealers, major market participants include financial institutions and other corporations, international organizations such as the World Bank, government-sponsored enterprises, corporate bond and mortgage-backed securities dealers, and hedge funds.

The swap market is one of the most active segments of the global fixedincome market. The introduction, in the mid-1980s, of master swap agreements, which are standardized legally binding agreements that detail the rights and obligations of each party in the swap, helped enhance market liquidity. Rather than spending time and resources on bilateral negotiations on the terms and language of individual contracts, such master agreements, which were sponsored by ISDA - the International Swaps and Derivatives Association - allowed market participants to converge to a common set of market practices and standards. Attesting to the liquidity of the market, typical bid-asked spreads are substantially narrower for swaps than those corresponding to even the most liquid corporate bonds.

As the swap market has grown in size and liquidity, so have dealers' exposures to each other and, in response, the practice of posting collateral 
that can be used to limit potential default-related losses in swaps has become increasingly widespread even among major market participants, as opposed to being limited to agreements with counterparties of lower credit quality. Also widespread, indeed virtually universal, is the practice of netting, which means that, rather than exchanging fixed and floating payments on the dates specified in the swap contract, the values of the two payments are netted, and only the party with a net amount due transfers funds to its counterparty.

\subsection{Swap valuation}

Consider an interest rate swap entered at time-t, with simultaneous exchanges of payments at dates $S_{i}, i=1, \ldots, n$, and a notional amount of $\$ 1$. Let $Y\left(t, S_{n}\right)$ denote the fixed rate written into the swap agreement, expressed on an annual basis. The floating-rate payments are assumed to be LIBOR flat so that, at each payment date $S_{i}$, the fixed-rate receiver pays $\delta_{i} L\left(S_{i-1}, S_{i}\right)$ to its swap counterparty and receives in return the amount $\delta_{i} Y\left(t, S_{n}\right)$, where $\delta_{i}$ is the accrual factor that pertains to period $\left[S_{i}, S_{i+1}\right]-$ e.g., if the swap involves semiannual payments, $\delta_{i}=0.5$ - and $L\left(S_{i-1}, S_{i}\right)$ is the corresponding LIBOR, also expressed on an annual basis. ${ }^{1}$

A simple approach to value such a swap is to compute the market values of its fixed- and floating-rate payments separately. For a fixed-rate receiver, the market value $V^{(S W A)}(t, S)$ of the swap is the difference between the time$t$ market value of the fixed leg, $V^{(F X)}(t, S)$, and that of the floating leg, $V^{(F L)}(t, S)$, where $S \equiv\left[S_{1}, S_{2}, \ldots, S_{n}\right]$.

Assuming that there is no risk that either party in the swap will renege on its obligations, i.e. there is no counterparty credit risk, the valuation of the floating and fixed legs of the swap is relatively straightforward. In particular,

\footnotetext{
${ }^{1}$ For ease of exposition, I ignore the different day-count conventions of the money and bond markets, which would affect the accrual factors used in the evaluation of the fixed and floating legs of the swap. These conventions, however, are explicitly taken into account in the empirical work described in later sections.
} 
I assume that the future payments associated with both legs are discounted based on the same zero-coupon yield curve, with no adjustment for the credit quality of individual counterparties. For the fixed leg I can write

$$
V^{(F X)}(t, S)=\sum_{i=1}^{n} \delta_{i} Y\left(t, S_{n}\right) P\left(t, S_{i}\right)
$$

where $P\left(t, S_{i}\right)$ is the time- $t$ price of a zero-coupon bond that matures at $S_{i}$, which is the time- $t$ value of $\$ 1$ to be received at $S_{i}$.

To value the floating leg of the swap, I rely on a simple investment strategy that exactly replicates its cash flow: At time $t$ an investor sells a zero-coupon bond that matures at $S_{n}$ and invests $\$ 1$ into a LIBOR-paying bank account, for a net cash outlay of $1-P\left(t, S_{n}\right)$. The bond has a face value of $\$ 1$, and the bank deposit pays an interest rate of $L\left(t, S_{1}\right)$ per annum, where $S_{1}$ is the maturity date of the deposit and $L\left(t, S_{1}\right)$ has a compounding frequency of $\delta_{1} \equiv S_{1}-t$. At time $S_{1}$, the investor receives $1+\delta_{1} L\left(t, S_{1}\right)$ from the bank, reinvests $\$ 1$ into another LIBOR-paying deposit, this one maturing at $S_{2}$ and paying the interest rate $L\left(S_{1}, S_{2}\right)$, and ends up with a net cash flow of $\delta_{1} L\left(t, S_{1}\right)$. The investors keeps on following this same strategy at times $S_{i}, i=2, \ldots, n-1$, receiving a net payment of $\delta_{i} L\left(S_{i-1}, S_{i}\right)$ in each occasion. Lastly, at time $S_{n}$, the investor receives $1+\delta_{n} L\left(S_{n-1}, S_{n}\right)$ from the bank, pays back the face value of the bond issued at $t$, receiving a net cash flow of $\delta_{n} L\left(S_{n-1}, S_{n}\right)$.

Note that the cash flow of the above investment strategy matches exactly the floating-rate payments of the swap. As a result, in the absence of arbitrage opportunities, the time- $t$ value of the swap's floating leg should then be equal to the time- $t$ cash outlay of the investment strategy. Thus,

$$
V^{(F L)}(t, S)=1-P\left(t, S_{n}\right)
$$


which implies that the time- $t$ value of the swap for a fixed-rate receiver is

$$
V^{(S W A)}(t, S)=\sum_{i=1}^{n} \delta_{i} Y\left(t, S_{n}\right) P\left(t, S_{i}\right)-1+P\left(t, S_{n}\right)
$$

\subsection{Par swap rates and forward rates}

It typically costs nothing to enter into a vanilla swap, which implies that the swap rate written into the contract is such that the swap has zero market value at its inception. Solving (3) for $Y\left(t, S_{n}\right)$ while setting $V^{(S W A)}(t, S)=0$, I obtain the following expression for the "par" swap rate $Y^{*}\left(t, S_{n}\right)$

$$
Y^{*}\left(t, S_{n}\right)=\frac{1-P\left(t, S_{n}\right)}{\sum_{i=1}^{n} \delta_{i} P\left(t, S_{i}\right)}
$$

For the purposes of this paper, it will be convenient to express $P\left(t, S_{i}\right)$ in terms of simple (discretely compounded) forward rates. It can be shown that the time- $t$ forward LIBOR that corresponds to the future period $\left[S_{i-1}, S_{i}\right]$ can be written as

$$
h\left(t, S_{i-1}, S_{i}\right)=\delta_{i}^{-1}\left[\frac{P\left(t, S_{i-1}\right)}{P\left(t, S_{i}\right)}-1\right]
$$

Note that, starting with $i=1$-and defining $S_{0} \equiv t$-I can solve (5) recursively to write zero-coupon bond prices in terms of simple forward rates. This allows me to express par swap rates entirely as a function of the forward LIBOR curve, $h\left(t, S_{j-1}, S_{j}\right), j=1,2, \ldots, n$,

$$
Y^{*}\left(t, S_{n}\right)=\frac{1-\prod_{j=1}^{n}\left[1+\delta_{j} h\left(t, S_{j-1}, S_{j}\right)\right]^{-1}}{\sum_{i=1}^{n} \prod_{j=1}^{i}\left[1+\delta_{j} h\left(t, S_{j-1}, S_{j}\right)\right]^{-1}}
$$

Equation (6), which is a model-independent relationship, plays a central role in the reminder of this paper. It implies that, for a given position of the forward LIBOR curve, one can synthesize par swap rates, which, in the absence of arbitrage opportunities and liquidity and credit-quality differentials 
between the swap and forward LIBOR markets, should correspond to the swap rates quoted in the marketplace. Hence, under the market conditions just described, one can think of (6) as the fair value of the par swap rate.

\section{Counterparty Credit Risk in Swaps}

In the previous section, I made two main simplifying assumptions to outline a simple methodology for determining the fair market value of an interest rate swap. First, I assumed the absence of counterparty credit risk in the derivation of the expression for the par swap rate. Second, in establishing a link between swaps and the forward LIBOR curve, I assumed that the two corresponding markets are equally liquid across all maturities. In this section, I shall assess the likely consequences of relaxing the first of these assumptions by examining theoretical and empirical results regarding the importance of counterparty credit risk in the determination of swap rates. I shall turn to the second assumption in the next section.

There is a vast literature in which counterparty credit risk in swaps is examined, with some studies dating back to the early years of the market. For instance, Cooper and Mello (1991) used a partial equilibrium framework to model the default risk premium embedded in swap rates and found that, although uncollateralized swaps do entail some counterparty credit risk exposure, such an exposure is substantially lower than that in related debt market instruments such as fixed- and floating-rate notes. In particular, given the netting provisions of swap contracts (discussed in Section 2), the counterparties are exposed only to the net difference between cash flows on the two synthetic debt contracts underlying the swap.

Another relatively early work on the importance of counterparty risk in swaps is that of Sorensen and Bollier (1994), who used an option theoretic framework that explicitly took into account both bilateral risk - or the fact that counterparties are exposed to each other's credit risk - and the effects of 
the slope of the yield curve on the determination of swap rates. They found that, when the yield curve steepens because of greater odds of higher interest rates in the future, the market value of fixed-rate paying positions in swaps becomes more likely to rise than to fall, leaving the holders of such positions more exposed to their swap counterparties, the floating-rate payers. (The reverse would be true in a flattening yield curve environment.) Sorensen and Bollier (1994) reported that adjustments to swap rates because of the credit risk of the counterparty can range from less than one basis point to more than 15 basis, but adjustments in excess of 10 basis points corresponded to swaps arranged with speculative-grade firms - who are not typical counterparties in swaps - under the most unfavorable term structure environments.

In practice, the role of counterparty credit risk in the determination of swap rates could be even lower than the relatively small effects suggested by Cooper and Mello (1991) and Sorensen and Bollier (1994). In particular, their analyses did not consider some important institutional details of the market, many of which are specifically designed to address issues related to the creditworthiness of potential counterparties. Such institutional details are at the heart of the discussion by Litzenberger (1992), who argued that swap dealers typically do not vary quoted swap rates with the credit quality of the prospective counterparty, instead adopting the practice of either rejecting counterparties with weaker credit ratings or requiring them to adopt one or more of the credit enhancement techniques described in Section 2.

More recent theoretical work has tended to confirm Litzenberger's main conclusions. For instance, Duffie and Huang (1996) proposed a model of asymmetric default risk that takes into account both the default characteristics of the counterparties and the probability distribution of the potential paths taken by the future value of the swap itself. The latter issue was not examined explicitly by Sorensen and Bollier (1994), and Duffie and Huang found even smaller effects of counterparty credit risk on swap rates than did Sorensen and Bollier. They reported that swap spreads are virtually insen- 
sitive to the credit quality of the counterparties, a result that, similar to the above mentioned paper by Cooper and Mello (1991), depended importantly on the netting provisions of swap contracts. Huge and Lando (1999) extended the Duffie-Huang framework to explicitly take into account the credit rating of each counterparty and to allow additional credit enhancement mechanisms in swap agreements, such as credit triggers. Their theoretical work, too, found little scope for counterparty credit risk to affect swap rates, and, indeed, recent papers on the determinants of swap rates abstract from credit risk questions altogether (e.g., He, 2000 and Liu, Longstaff, and Mandell, 2002).

Nonetheless, Minton (1997) interpreted results of her empirical analysis of swap rates as casting some doubt on Litzenberger's main conclusions and on the theoretical results obtained by Duffie and Huang and others. Using futures rates as proxies for forward rates, she used the methodology described in Section 2 to construct swap rates implied by the no-arbitrage relationship between swaps and forward rates. She found that (6) failed to hold in her sample. She then reported on evidence that suggested that proxies for concerns about counterparty credit risk - such as spreads between yields on corporate bonds and those on U.S. Treasury securities - played, in some cases, a statistically significant role in the determination of swap rates. In particular, Minton argued that the fact that actual swap rates differ from those implied by the futures market-where the futures exchange and margining provisions essentially eliminate worries about counterparty credit risk-could be interpreted as a sign of counterparty risk concerns in the interest rate swap market.

More recently, however, Gupta and Subrahmanyam (2000) provided some counter evidence to Minton's findings. Although Gupta and Subrahmanyam's focus was on whether interest rate swaps were correctly priced in the early years of the swap market, they also examined the relationship between swap rates and proxies for counterparty credit risk similar to the ones used by 
Minton. They found that, while statistically significant in some instances, the effect of counterparty risk on swap rates is so small as to be economically insignificant. Gupta and Subrahmanyam also argued that Minton's approach of using futures as direct proxies for forward rates introduces a significant bias in the pricing of interest rate swaps because such a practice ignores the differential convexity of the two contracts. ${ }^{2}$ Accordingly, they used various interest rate models to derive a convexity adjustment for futures rates (relative to forward rates) and argued that the spread between actual swap rates and those implied by unadjusted futures rates moves largely in line with the convexity adjustment term and not, as suggested by Minton, as a result of counterparty credit risk.

Minton's (1997) and Gupta and Subrahamanyam's (2000) work, as well as most of the empirical papers referenced above, predate recent episodes of stress in financial markets, ranging from the Asian financial crisis of 1997 to the bout of financial market uncertainty surrounding the century-date change. ${ }^{3}$ Thus, the question of whether credit enhancement mechanisms and netting arrangements have been sufficiently effective in insulating swap rates from concerns about counterparty risk during times of turmoil in the broader financial markets remains largely unanswered. Addressing this empirical issue is one of the main intended contributions of this paper. I extend the empirical analysis of Minton (1997) and Gupta and Subrahmanyam (2000) by examining the likely importance of concerns about counterparty credit risk in the determination of swap rates in a larger and more recent sample and, more important, in a framework that explicitly allows for such concerns to potentially play a more prominent role during times of financial market

\footnotetext{
${ }^{2}$ In addition to Gupta and Subrahmanyam (2000), the relationship between forward and futures contracts has been analyzed in several previous works, including Cox, Ingersoll, and Ross (1981), Sundaresan (1991), Burghardt, Belton, Lane, Luce, and McVey (1991), Kamara (1994), Muelbroek (1992), and Grinblatt and Jegadeesh (1996). The next section discusses the convexity adjustment factor in some detail.

${ }^{3}$ Gupta and Subrahmanyam (2000) used data through 1996.
} 
stress. $^{4}$

\section{Futures-Implied Swap Rates}

I now turn to the other main simplifying assumption implicitly made in Section 2, the one that asserted that the forward LIBOR quotes in the righthand-side of (6) were derived from a market that is as liquid as that for interest rate swaps. In reality, liquidity in the LIBOR market is highly concentrated in instruments maturing in less than two years, and the same is true for the forward rate agreement market, where forward LIBOR contracts are commonly negotiated. As a result, assessing the no-arbitrage relationship between par swap rates and the forward LIBOR curve is not as simple as (6) suggests. Instead of directly relying on (6), many market practitioners and researchers have often turned to eurodollar futures contracts, which are highly liquid close cousins to forward LIBOR contracts, to determine fair valuations and potentially identify mispricings across the LIBOR and swap markets.

\subsection{Anatomy of an eurodollar futures contract}

At its core, an eurodollar futures contract is very similar to a forward LIBOR contract. Let $H\left(t, S_{i-1}, S_{i}\right)$ be the time- $t$ annualized interest rate written into a newly entered futures contract, where the interest rate will be applied to a future period $\left[S_{i-1}, S_{i}\right]$, and I assume that the notional amount of the contract is $\$ 1$. In principle, similar to a forward contract, one of the parties to the futures contract has agreed to borrow $\$ 1$ at time $S_{i-1}$ and repay it at time $S_{i}$ plus an interest payment of $\delta_{i} H\left(t, S_{i-1}, S_{i}\right)$. Also analogous to most forward

\footnotetext{
${ }^{4}$ Other papers that address the issue of counterparty credit risk in swaps include Belton (1987), Sun, Sundaresan, and Wang (1993), Duffie and Singleton (1997), and Grinblatt (2001).
} 
LIBOR contracts, the rate $H\left(t, S_{i-1}, S_{i}\right)$ is such that the futures contract has zero market value at its inception, in which case $H\left(t, S_{i-1}, S_{i}\right)$ is called the time- $t$ futures rate for future lending/borrowing at $\left[S_{i-1}, S_{i}\right] .^{5}$

In the United States, eurodollar futures contracts are traded primarily at the Chicago Mercantile Exchange (CME), with the maturity of the underlying futures rates, $S_{i}-S_{i-1}$, most commonly corresponding to three months. As for the maturities of the contracts themselves, $S_{i-1}-t$, they range from a few days to as far out as ten years. Eurodollar futures contracts are among the most liquid futures contracts traded in the CME and the Chicago Board of Trade, the two major futures exchanges in the United States.

Combined with their high liquidity, the close resemblance between futures and forward contracts, makes eurodollar futures rates potentially useful proxies for the forward LIBOR rates that appeared in equation (6). Nonetheless, futures and forward contracts do differ in a subtle but important way: Futures contracts are marked to market on a daily basis and, unlike a forward contract - which pays out only at its maturity - margin account balances are adjusted accordingly throughout the life of the futures contract. This difference in the timing of cash flows associated with the two contracts has important implications for their pricing.

\subsection{Futures and forward rates in a generic spot rate model}

All the results that I have derived thus far are model independent. To take a closer look at the difference between futures and forward rates, and the implications of using the former in the no-arbitrage relationship between swap and forward rates - equation (6) - I will now turn to a relatively simple modeling framework that is general enough to encompass a variety of well-known spot interest rate models. In particular, I start by assuming that forward

\footnotetext{
${ }^{5}$ Throughout this paper, I assume the equality between lending and borrowing rates.
} 
and futures rates are functions $f\left(r(t), t, S_{i-1}, S_{i}\right)$ and $F\left(r(t), t, S_{i-1}, S_{i}\right)$, respectively, of the spot rate $r(t)$ - defined as the instantaneous short rate at time t-where the specific forms of $f($.$) and F($.$) are yet to be determined.$

Regarding $r(t)$, I assume that it follows a stochastic process with drift $\mu(r, t)$ and diffusion $v(r, t)$ under the real (objective) probability measure.

$$
d r(t)=\mu(r, t) d t+v(r, t) d \bar{X}(t)
$$

and where $d \bar{X}(t)$ is an infinitesimal increment in a standard Brownian motion under the objective measure. I shall refer to (7) as a generic spot rate model for as long as I leave the functional forms of $\mu(r, t)$ and $v(r, t)$ unspecified.

Futures contracts. To derive an expression for the futures rate under the generic spot rate model, I follow a valuation approach similar to the BlackScholes methodology for valuing calls and puts. This allows me to write down the partial differential equation that $F($.$) must satisfy in an economy$ without arbitrage opportunities:

$$
\frac{\partial F}{\partial t}+\frac{v(r, t)^{2}}{2} \frac{\partial^{2} F}{\partial r^{2}}+[\mu(r, t)-\lambda(r, t) v(r, t)] \frac{\partial F}{\partial r}=0
$$

where $\lambda($.$) denotes the market price of risk. The final condition given by$

$$
F\left(r\left(S_{i-1}\right), S_{i-1}, S_{i-1}, S_{i}\right)=L\left(S_{i-1}, S_{i}\right)
$$

i.e., the futures rate must converge to the spot rate.

At this point, I can invoke the Feynman-Kac stochastic representation formula to obtain the function $F($.$) that solves the problem defined by (8)$ and (9):

$$
F\left(r(t), t, S_{i-1}, S_{i}\right)=\tilde{E}_{t}\left[L\left(S_{i-1}, S_{i}\right)\right]
$$

where $\tilde{E}_{t}[$.$] denotes an expectation based on the risk-adjusted (risk-neutral)$ 
process for $r(t)$ :

$$
d r(t)=[\mu(r, t)-\lambda(r, t) v(r, t)] d t+v(r, t) d X(t)
$$

and where $d X(t)$ is an infinitesimal increment in a standard Brownian motion under the risk-neutral measure.

Equation (10) is the familiar result that the futures rate corresponds to the risk-adjusted expectation of the interest rate underlying the contract.

Forward contracts. The derivation of the forward LIBOR curve in the context of the spot rate model is straightforward. Consider a forward LIBOR contract written at time $t$ for borrowing $\$ 1$ at the future period $\left[S_{i-1}, S_{i}\right]$. The contract will be cash-settled at time $S_{i-1}$ and its payoff will be based on the difference between the $L\left(S_{i-1}, S_{i}\right)$ - the actual LIBOR prevailing at $S_{i-1}$ for lending and borrowing until $S_{i}$-and the rate $K^{*}$ specified in the contract. ${ }^{6}$ I can use the risk-neutral valuation approach to write out the time- $t$ value of this forward contract

$$
V^{(F W D)}\left(r(t), t, S_{i-1}, S_{i}\right)=\tilde{E}_{t}\left\{e^{-\int_{t}^{S_{i-1}} r(s) d s} \delta_{i}\left[L\left(S_{i-1}, S_{i}\right)-K^{*}\right]\right\}
$$

where, as above, $\tilde{E}_{t}[$.$] denotes a conditional expectation computed under the$ risk-neutral probability measure.

Equation (12) has the intuitive result that the market value of the forward contract is just the risk-adjusted expectation of the present value of its payoff. Ordinarily, of course, it costs nothing to enter into a forward contract so that, in the absence of arbitrage opportunities, the rate $K^{*}$ specified in the contract is such that $V^{(F W D)}\left(r(t), t, S_{i-1}, S_{i}\right)=0$. Letting $f\left(r(t), t, S_{i-1}, S_{i}\right)$ denote

\footnotetext{
${ }^{6}$ This is basically the structure of a forward rate agreement (FRA), which is a commonly negotiated over-the-counter contract.
} 
the value of $K^{*}$ such that $V^{(F W D)}\left(r(t), t, S_{i-1}, S_{i}\right)=0$, I obtain

$$
f\left(r(t), t, S_{i-1}, S_{i}\right)=\frac{\tilde{E}_{t}\left[e^{-\int_{t}^{S_{i-1}} r(s) d s} L\left(S_{i-1}, S_{i}\right)\right]}{\tilde{E}_{t}\left[e^{-\int_{t}^{S_{i-1}} r(s) d s}\right]}
$$

which is the function that the forward LIBOR curve satisfies in the generic spot rate model.

The futures-forward differential. I am now ready to compare futures and forward rates in the context of the generic spot rate model. Using the fact that, for any two stochastic variables $z_{i}$ and $z_{j}, \tilde{E}_{t}\left[z_{i} z_{j}\right]=\tilde{E}_{t}\left[z_{i}\right] \tilde{E}_{t}\left[z_{j}\right]+$ $\tilde{c} v_{t}\left[z_{i}, z_{j}\right]$, where $\tilde{c} v_{t}\left[z_{i}, z_{j}\right]$ denotes the covariance of $z_{i}$ and $z_{j}$ under the risk neutral measure, I can rewrite (13) as

$$
f\left(r(t), t, S_{i-1}, S_{i}\right)=F\left(r(t), t, S_{i-1}, S_{i}\right)+\frac{\tilde{c v}_{t}\left[e^{-\int_{t}^{S_{i-1}} r(s) d s}, L\left(S_{i-1}, S_{i}\right)\right]}{\tilde{E}_{t}\left[e^{-\int_{t}^{S_{i-1}} r(s) d s}\right]}
$$

where, to arrive at the above expression, I used (10).

Note that the last term of the above equation is the so-called convexity adjustment that translates futures rates into forward rates. When the short rate is deterministic, the covariance term is zero and forward and futures rates coincide, as demonstrated by Cox, Ingersoll, and Ross (1981) and many others.

\subsection{Results from a specific spot rate model}

One can write out an explicit formula for the difference between futures and forward rates by making specific assumptions about the drift and diffusion terms of the generic spot rate model (11). I show below how this can be done with the no-arbitrage model of Ho and Lee (1986). The Ho-Lee model has the advantage that it is extremely simple and tractable, and this is my main motivation for using it in this illustrative subsection. Its simplicity, however, 
comes at the cost of some unrealistic implications, discussed in Section 7, where I also examine results based on other models.

In the Ho-Lee model, the drift and the diffusion terms of the risk-neutral process for $r(t),(11)$, become $\mu(r, t)-\lambda(r, t) v(r, t)=\theta(t)$ and $v(r, t)=\sigma$, where $\sigma$ denotes the volatility of the short rate, and the drift $\theta(t)$ is chosen at each point in time such that the theoretical bond prices implied by the model fit the observed term structure of interest rates exactly.

Using a standard hedging argument, one can show that the time- $t$ price $P(r(t), t, S)$ of a zero-coupon bond maturing at time $S$ satisfies the following partial differential equation

$$
\frac{\partial P}{\partial t}+\frac{\sigma^{2}}{2} \frac{\partial^{2} P}{\partial r^{2}}+\theta \frac{\partial P}{\partial r}-r P=0
$$

with final condition given by $P(r(S), S, S)=1$. The solution to this PDE has the form

$$
P(r(t), t, S)=e^{-A(t, S)-B(t, S) r(t)}
$$

where $B(t, S) \equiv S-t$ and $A(t, S) \equiv \int_{t}^{S} \theta(s)[s-S] d s+\frac{\sigma^{2}[S-t]^{3}}{6}$, and, to ensure that the model fits observed bond prices exactly, $\theta(s)=\frac{\partial f^{*}(t, s)}{\partial s}+$ $\sigma^{2}[s-t]$, where $f^{*}(t, s)$ denotes the instantaneous time-t forward for lending or borrowing at time $s$, for $s>t$, derived directly from observed market prices.

In light of (5) and (16), the simple time- $t$ forward rate that corresponds to the future period $\left[S_{i-1}, S_{i}\right]$ can be written as:

$$
f\left(r(t), t, S_{i-1}, S_{i}\right)=\frac{1}{\delta_{i}}\left[e^{A\left(S_{i-1}, S_{i}\right)+B\left(S_{i-1}, S_{i}\right) \tilde{E}_{t}\left[r\left(S_{i-1}\right)\right]-\frac{\sigma^{2}}{2} p\left(t, S_{i-1}, S_{i}\right)}-1\right]
$$

where $p\left(t, S_{i-1}, S_{i}\right) \equiv\left(S_{i-1}-t\right)\left(S_{i}-t\right)\left(S_{i}-S_{i-1}\right)$, and, given (11) and $\theta(t)$,

$$
\tilde{E}_{t}\left[r\left(S_{i-1}\right)\right]=r(t)+\int_{t}^{S_{i-1}} \theta(s) d s=f^{*}\left(t, S_{i-1}\right)+\frac{\sigma^{2}}{2}\left(S_{i-1}-t\right)^{2}
$$


In the Ho-Lee model, the futures rate $F\left(t, S_{i-1}, S_{i}\right)$ becomes

$$
F\left(r(t), t, S_{i-1}, S_{i}\right)=\frac{1}{\delta_{i}}\left[e^{A\left(S_{i-1}, S_{i}\right)+B\left(S_{i-1}, S_{i}\right) \tilde{E}_{t}\left[r\left(S_{i-1}\right)\right]+\frac{1}{2} \tilde{V}_{t}\left[r\left(S_{i-1}\right)\right] B\left(S_{i-1}, S_{i}\right)^{2}}-1\right]
$$

where $\tilde{V}_{t}\left[r\left(S_{i-1}\right)\right] \equiv \sigma^{2}\left(S_{i-1}-t\right)$ denotes the conditional variance of $r\left(S_{i-1}\right)$, computed under the risk-neutral measure, based on information available at time $t$.

From equations (17) and (18) I can derive the convexity adjustment, $\xi\left(r(t), t, S_{i-1}, S_{i}\right) \equiv F\left(r(t), t, S_{i-1}, S_{i}\right)-f\left(r(t), t, S_{i-1}, S_{i}\right)$, that converts observed eurodollar futures rates into implied forward rates,

$\xi\left(r(t), t, S_{i-1}, S_{i}\right)=q\left(r(t), t, S_{i-1}, S_{i}\right)\left[1-e^{-\frac{\sigma^{2}}{2}\left(S_{i-1}-t\right)\left(S_{i}-S_{i-1}\right)\left[\left(S_{i-1}-t\right)+2\left(S_{i}-S_{i-1}\right)\right]}\right]$

where $q\left(r(t), t, S_{i-1}, S_{i}\right) \equiv F\left(r(t), t, S_{i-1}, S_{i}\right)+\delta_{i}^{-1}$. It can be shown that the convexity adjustment is positive and that it is an increasing function both of the volatility $\sigma$ of the short rate and of the maturity $\left(S_{i-1}-t\right)$ of the futures contract. ${ }^{7}$ Thus, for instance, the longer the maturity of a futures contract, the more its corresponding futures rate will overstate the forward rate that pertains to a forward contract of same maturity.

The results obtained thus far allow us to use the Ho-Lee model to translate futures rates into forward rates and, in light of (6), obtain the corresponding futures-implied par swap rate:

$$
\hat{Y}\left(t, S_{n}\right)=\frac{1-\prod_{j=1}^{n}\left[1+\delta_{j} \hat{f}\left(r(t), t, S_{j-1}, S_{j}\right)\right]^{-1}}{\sum_{i=1}^{n} \prod_{j=1}^{i}\left[1+\delta_{j} \hat{f}\left(r(t), t, S_{j-1}, S_{j}\right)\right]^{-1}}
$$

where I used the symbols $\hat{Y}($.$) and \hat{f}($.$) to denote model-dependent futures-$ implied par swap and forward rates, respectively, as opposed to the symbols

\footnotetext{
${ }^{7} \xi\left(r(t), t, S_{i-1}, S_{i}\right)$ is also increasing in $\left(S_{2}-S_{1}\right)$, the maturity of the underlying LIBOR deposit, but this relationship is less important for my purposes given my focus on contracts written on three-month LIBOR.
} 
$Y^{*}($.$) and f($.$) , which I used to represent observed par swap rates and the$ forward rates that would prevail in a fully liquid forward LIBOR market.

I shall henceforth refer to $\hat{Y}\left(t, S_{n}\right)$ as the synthetic swap rate. As demonstrated above, such a rate is jointly determined by the eurodollar futures curve and the particular spot rate model used to compute the convexity adjustment. To check the sensitivity of my empirical findings to the assumptions made in the Ho-Lee model, I shall follow the spirit of Gupta and Subrahmanyam (2000) and report results for a variety of well-known interest rate models.

\section{Synthetic Swap Rates}

I now take the theoretical results derived in earlier sections and apply them to the data in order to examine whether they were valid over the past decade, in general, and during times of market stress in particular. Again, the basic premise of the analysis is that I can use synthetic swap rates computed from convexity-adjusted futures rates as benchmark swap rates involving no adjustment for counterparty credit risk, as this is absent in the exchangebased futures market. Given these synthetic rates, I examine the extent to which they differ from actual swap rates and whether such differences can be explained by common proxies for counterparty credit risk. I use weekly quotes on one-, three-, and six-month LIBOR, two-, three-, five-, seven-, and ten-year swap rates, three-month eurodollar futures rates for contract maturities extending through ten years, and prices of European options to enter into five-year swaps (swaptions), with expiration dates ranging from six months to five years. The data are sampled from quotes which extend from January 1994 to March 2002. 


\section{$5.1 \quad$ Futures-implied swap rates}

The first step in the construction of swap rates implied by eurodollar futures contracts involves using observed futures rates to construct a string of futures contracts with settlement dates that coincide with the payment dates that correspond to the swap rate that I want to synthesize. At a given point in time, I observe swap rates for fixed maturities - e.g., two, five, and ten years - but the quoted eurodollar futures rates I use are for contracts written with reference to fixed three-month periods in the future and, thus, their maturities are time-varying. Moreover, the payment dates of the swaps typically do not coincide with the settlement dates of the futures contracts. To address this mismatch between payment dates and maturities of swaps and futures, I interpolated the eurodollar futures curve for each date in the sample and picked out those points in the curve that allowed me to exactly mimic the timing of the payments associated with the swap rate I want to synthesize. ${ }^{8}$

In Figure 2, I compare average swap rates quoted in the marketplace to those implied by interpolated eurodollar futures rates, based on equation (6) with $f($.$) substituted by F($.$) as is implicit in the work of Minton (1997) and$ others who used futures rates as direct proxies for forward rates. The solid line shows the sample average of market swap rates, where the average is taken across the time series dimension. The dashed line is analogously characterized for the futures-implied swap rates. The figure implies that market and futures-implied rates are virtually identical, on average, for maturities up to around four years, suggesting that the convexity adjustment is negligible for short maturities. As we look farther up the curve, however, the average difference between futures-implied swap rates and market-observed swap rates increases with the maturity of the swap. This is consistent with

\footnotetext{
${ }^{8}$ I interpolated the futures rate curve by using conventional cubic spline interpolation methods. For each date $t$ in the sample, I used short-term LIBOR quotes to bridge any gaps between $t$ and the beginning of the first futures contract.
} 
the theoretical results derived thus far, which showed that the spread between futures and forward rates is positive and increasing in the maturity of the contracts. ${ }^{9}$

\subsection{Estimating the size of the convexity correction}

I start with the modeling framework described in Section 4, where I noted that the Ho-Lee model implies that the size of the convexity adjustment depends primarily on the maturity, $\left(S_{i-1}-t\right)$, of the futures contract and the volatility, $\sigma$, of the short rate. While the first of these variables is written into the contract, the second has to be inferred from observed data.

Calibration of the volatility parameter. For each date $t$ in the sample, I combined theoretical swaption prices implied by the spot rate model with actual swaption prices quoted in the marketplace to obtain a market-implied value of $\sigma$. I used weekly data on prices of five-year swaptions with expiration dates ranging from six months to five years out.

I relied on standard numerical procedures to search for the value of $\sigma$ at each point in time that, given the then prevailing yield curve, provided the best fit between swaption prices quoted in the market and the theoretical swaption prices derived from the Ho-Lee model. The first four panels of Figure 3 compare actual and theoretical swaption prices; the prices shown correspond to six-month/five-year, one-year/five-year, two-year/fiveyear, and five-year/five-year swaptions. As can be seen, despite its simplicity, the model does a good job capturing the observed term-structure of swaption prices. The bottom panel shows the values of $\sigma$ that allowed the model to best fit the quoted prices. The average value of $\sigma$ over the sample, about

\footnotetext{
${ }^{9}$ Using (6), it can be shown that par swap rates are increasing functions of their underlying forward rates. Thus, if I use futures rates as proxies for forward rates in (6) the positive differential between futures and forward rates is such that futures-implied swap rates will overstate the actual swap rates quoted in the market place.
} 
0.01, falls within the range of estimates reported in other work, e.g. Hull (2000).

Given the calibrated values of $\sigma$, I now proceed to infer the size of the convexity adjustment implied by the model. The solid and dashed lines in Figure 4 show the average and futures-implied swap rates depicted in Figure 2 , and the dotted line shows average swap rates implied by convexity-adjusted futures rates, where the latter were constructed based on equation (20). As shown in Figure 4, the convexity-adjusted, futures-implied swap curve is, on average, everywhere less than five basis points away from the market swap rates, suggesting that the Ho-Lee convexity differential between futures and forward rates explains most of the average spread between market and futures-implied swap rates. This implies that concerns about counterparty credit risk in swaps generally do not appear to be a significant factor in the determination of market swap rates. Figure 5 shows market and synthetic swap rates for a given date (the last date in the sample). The close fit between market and synthetic swap rates is remarkable.

\section{Empirical Analysis of Synthetic and Mar- ket Rates}

Thus far I have mostly focused on the relationship between average values of market and synthetic swap rates. I now turn my attention to the behavior of these two sets of rates, considered over time and across different maturities, especially to the extent to which they deviate from one another. Figure 6 provides a first look at the data, showing differences between $Y^{*}\left(t, S_{n}\right)$ and $\hat{Y}\left(t, S_{n}\right)$ for all swap rates and dates in the sample. As can be seen, these differences are generally very close to zero.

In order to look more closely at the differences between market and syn- 
thetic swap rates, I started by estimating the following simple regression,

$$
Y^{*}\left(t, S_{n}\right)=\beta_{n, 0}+\beta_{n, 1} \hat{Y}\left(t, S_{n}\right)+e_{n, t}
$$

for $t=1,2, \ldots, \bar{T}$, where $Y^{*}\left(t, S_{n}\right)$ is the time- $t$ fixed rate quoted for a swap that matures at $S_{n}, \hat{Y}\left(t, S_{n}\right)$ is the synthetic swap rate, defined in equation (20), and $e_{n, t}$ is an equation residual, which is assumed to be a normally distributed random variable with zero mean.

I ran this regression for five different maturities: two, three, five, seven, and ten years. The results are reported in panel A of Table 1. For each maturity, the market rate moves virtually one-to-one with the corresponding synthetic swap rate. Indeed, the null of a unit coefficient on the synthetic rate can be rejected only for the five- and ten-year rates, and even for these maturities the point estimates are very close to one. Still, to allay the concerns of those who might worry about unit roots in market interest rates, I also estimated equation (21) in first differences

$$
\Delta Y^{*}\left(t, S_{n}\right)=\gamma_{n, 0}+\beta_{n, 1} \Delta \hat{Y}\left(t, S_{n}\right)+u^{(1)}(t, n)
$$

where $\Delta Y$ denotes the first difference of $Y$ and $u^{(1)}(t, n)$ is a normally distributed, zero-mean residual.

Estimation results for the first-differences specification are reported in panel B of Table 1. The restriction of a zero intercept in (22) cannot be rejected at the usual significance levels, but the null of a unit slope is easily rejected, although, as before, the estimated values of $\beta_{1, n}$ are all very close to one. The joint hypothesis that $\left[\gamma_{0, n}, \beta_{1, n}\right]=[0,1]$ is rejected for all but the ten-year rate regression. Together, these results suggest a tight relationship between market and synthetic swap rates throughout the sample, potentially leaving little room for counterparty credit risk concerns to play an important role in the determination of market swap rates. 


\subsection{Testing for counterparty credit risk effects}

The results reported in Table 1 suggest that market swap rates move nearly one-to-one with synthetic swap rates derived from Ho-Lee convexity-adjusted futures rates. It is possible, however, that there are other factors that are systematically behind fluctuations in market swap rates. Table 2 summarizes the findings of regressions that examine whether changes in a common proxy for counterparty credit risk are likely to be one of these missing factors. In particular, I am interested in whether changes in corporate credit risk spreads have explanatory power for changes in market swap rates over and above that provided by changes in the synthetic swap rates. I ran the following regressions for the same maturities listed in Table 2:

$$
\Delta Y^{*}\left(t, S_{n}\right)=\gamma_{n, 0}+\beta_{n, 1} \Delta \hat{Y}\left(t, S_{n}\right)+\beta_{n, 2} \Delta Y C(t)+u^{(2)}(t, n)
$$

where $Y C(t)$ is the spread between yields on BBB- and AAA-rated corporate bonds with maturities between seven and ten years, and $u^{(2)}(t, n)$ is a normally distributed residual, assumed to have zero mean. As can be seen in the table, the estimated values of $\beta_{n, 2}$ were statistically insignificant for all ma-

turities, implying that changes in this measure of the market's perception of counterparty credit risk have generally not been a factor in the determination of market swap rates. This insignificance result was unchanged when I used either the spread of BBB-rated corporate bond yields over Treasury yields or the spread or BBB-rated corporate yields over AA-rated yields, instead of the BBB/AAA spread used in the regression results reported in Table 2.

I also ran regressions of the spread between market and synthetic swap rates on the various proxies for counterparty credit risk,

$$
\left[Y^{*}\left(t, S_{n}\right)-\hat{Y}\left(t, S_{n}\right)\right]=\tau_{n, 0}+\tau_{n, 1} Y C(t)+v^{(1)}(t, n)
$$

where $v^{(1)}(t, n)$ is the normally distributed residual, assumed to have zero 
mean. I found no systematic effects of $Y C$ on $[Y-\hat{Y}]$. The slope coefficient was often statistically insignificant and its sign varied from maturity to maturity. Moreover, for all maturities, the estimated coefficients were so small as to be economically insignificant: The absolute value of $\tau_{n, 1}$ was always less than 0.04, implying that a 100 basis point change in $Y C$ is typically associated with no more than a 4 basis point change in $\left[Y^{*}\left(t, S_{n}\right)-\hat{Y}\left(t, S_{n}\right)\right]$.

\subsection{Swap valuation during the 1998 market crisis}

Although the results obtained thus far have generally downplayed the importance of counterparty credit risk in the determination of swap rates, it may well be that market participants become especially sensitive to such risk during times of market stress. That would suggest, for instance, that the tight relationship between market and synthetic swap rates could have been significantly disrupted during the fall of 1998, when much of the global financial markets was in disarray following the Russian default and hedge fund crises. Did movements in market swap rates at that time systematically diverge from movements in synthetic rates? Would such a divergence, if any, be related to heightened concerns about counterparty credit risk? To address the first of these questions I augmented (22) as follows

$$
\Delta Y^{*}\left(t, S_{n}\right)=\gamma_{n, 0}+\beta_{n, 1} \Delta \hat{Y}\left(t, S_{n}\right)+\beta_{n, 3} \phi(t)+u^{(3)}(t, n)
$$

where $u^{(3)}(t, n)$ is normally distributed with zero mean. $\phi(t)$ is a dummy variable set to one between the weeks of August 21, 1998 and October 16, 1998 - roughly the time period that most people associate with the peak of the 1998 market crisis - and zero elsewhere. ${ }^{10}$ Thus, (25) allows the equation

\footnotetext{
${ }^{10}$ The week of August 21 immediately followed the Russian default and devaluation of August 17 and the week of October 16 followed the initial easing of monetary policy by the U.S. Federal Reserve, which appeared to have had a calming effect on financial markets. I also experimented with different time intervals for the 1998 crisis, and the main results were essentially unchanged.
} 
to have an intercept of $\gamma_{n, 0}+\beta_{n, 3}$ during the 1998 financial crisis - when $\phi(t)=$ 1 - and $\gamma_{n, 0}$ during other times - when $\phi(t)=0$. Intuitively, the equation allows for the possibility the market swap rates systematically moved away from their normal relationship with synthetic rates during the 1998 crisis, in the sense that the average weekly change in $Y^{*}($.$) during the crisis differed$ significantly what would be suggested by changes in $\hat{Y}($.$) alone.$

The estimation results related to (25) are summarized in panel A of Table 3. They suggest no statistically significant role for the dummy variable $\phi(t)$ in the equation intercept as the coefficient $\beta_{n, 3}$ cannot be statistically distinguished from zero.

To address the issue of whether swap market participants became particularly sensitive to changes in counterparty credit risk during the 1998 crisis, I also estimated the following relationship

$$
\Delta Y^{*}\left(t, S_{n}\right)=\gamma_{n, 0}+\beta_{n, 1} \Delta \hat{Y}\left(t, S_{n}\right)+\left[\beta_{n, 2}+\beta_{n, 4} \phi(t)\right] \Delta Y C(t)+u^{(4)}(t, n)
$$

where $u^{(4)}(t, n)$ is a normally distributed residual, assumed to have zero mean.

Estimation results based on (26) are reported in panel B of Table 3. The regressions failed to detect a statistically significant effect of the 1998 crisis on the sensitivity of market swap rates to the counterparty risk proxy for all of the maturities examined - the estimated value of $\beta_{n, 4}$ cannot be statistically distinguished from zero. These conclusions remained unchanged for the other two credit risk spreads mentioned above.

Regression results based on the spread between market and synthetic swap rates also failed to uncover a systematic effect of the 1998 crisis on swap rates. I estimated the following equation for all maturities analyzed in Table 3, which simultaneously allows for the 1998 crisis to affect both the intercept and the slope of (24),

$$
\left[Y^{*}\left(t, S_{n}\right)-\hat{Y}\left(t, S_{n}\right)\right]=\tau_{n, 0}+\tau_{n, 1} Y C(t)+\phi(t)\left[\tau_{n, 2}+\tau_{n, 3} Y C(t)\right]+v^{(2)}(t, n)
$$


where $v^{(2)}(t, n)$ is a normally distributed residual with zero mean.

With the exception of a very small but statistically significant $\tau_{n 3}$ coefficient for the two-year swap rate, I found no significant crisis effect on either the slope or the intercept of (27). The finding that the 1998 crisis did not appear to have a noticeable effect on the relationship between market and synthetic swap rates can also be checked informally by looking at the time series of regression residuals associated with equations (21) and (22). As can be seen in Figures 7 and 8, there does not appear to exist a systematic difference between the 1998 residuals and those of other years.

\section{Sensitivity Analysis}

The results obtained thus far suggest that concerns about counterparty credit risk seem to be largely mitigated by institutional details of the swaps market, such as the practices of netting and requiring collateral. Moreover, the findings are consistent with recent theoretical work-e.g. Duffie and Huang (1996) and Huge and Lando (1999) - and with the conclusions reached by Litzenberger (1992). Nonetheless, my results are based, in part, on the specific assumptions underlying the Ho and Lee model, and one might wonder about the extent to which these assumptions are are valid, and, more importantly, how sensitive the results are to the particular choice of spot rate model. Although the Ho and Lee framework has the advantage of being analytically tractable and easy to apply, in addition to providing an exact fit to the observed yield curve, it has some drawbacks, such as the fact that it allows for no mean-reversion in the short rate process, the property that all spot and forward rates have the same volatility, and the possibility of negative spot rates. As a result, both to check the sensitivity of the results to other modeling assumptions and to allay the concerns of those who might be unhappy with the Ho-Lee model for the short-rate process, I ran the same 
analysis described above for other widely used models. ${ }^{11}$

\subsection{The Hull and White model}

First, I looked at another no-arbitrage model, the one developed by Hull and White (1990). In its most common form, the Hull-White model assumes that the risk-neutral process for short rate is given by

$$
d r(t)=[\theta(t)-\operatorname{ar}(t)] d t+\sigma d X(t)
$$

where $X(t)$ is a standard Brownian motion, $\theta(t)$ is a deterministic function that, as in the Ho and Lee model, allows the model to be calibrated to exactly fit the observed yield curve, and $a$ and $\sigma$ are positive constants that need to be inferred from observable data such as market prices of swaptions of various maturities. ${ }^{12}$

As with the the Ho-Lee framework, I calibrated the model to observed swaptions prices so that, for each time $t, a$ and $\sigma$ are chosen in order to minimize the difference between actual and model-implied prices. I then subjected the synthetic swap rates implied by the Hull-White model to the same battery of tests reported above for the Ho-Lee framework. Results obtained with the Hull-White model led to virtually the same conclusions reported above, suggesting that my findings are not peculiar to the assumptions made by Ho and Lee.

\subsection{Estimated Vasicek-type models}

I also tested the sensitivity of my results to three alternative models, which were formally estimated, rather than calibrated. I used the one-factor model

\footnotetext{
${ }^{11}$ In appendix A, I provide formulae for the derivation of the convexity adjustment under each of the models examined in this paper.

${ }^{12}$ Note that the Hull-White model allows for mean reversion in the short rate: The speed of mean reversion is $a$, and the mean reversion level is given by $\theta(t) / a$.
} 
originally proposed by Vasicek (1977), a two-factor extension of the Vasicek model analyzed in Bomfim (2002), and the one-factor model developed by Cox, Ingersoll, and Ross (1985).

As in the Hull-White model, the Vasicek model assumes that the short rate follows a mean reverting process, but, unlike Hull and White, Vasicek assumes that the short rate reverts to a time-invariant level, $l$. Indeed, as the Vasicek model predates Hull and White's work, the Hull-White model is also called an extended Vasicek model.

The one-factor Vasicek model assumes that the short rate $r(t)$ evolves according to

$$
d r(t)=a[l-r(t)] d t+\sigma d \bar{X}(t)
$$

where, unlike the models examined thus far, the above equation corresponds to the evolution of $r(t)$ under the real probability measure.

The following two-factor version postulates a similar real process for the spot rate, except that the level of mean reversion of the spot rate is itself also assumed to be stochastic and mean reverting:

$$
\begin{aligned}
d r(t) & =a[l(t)-r(t)] d t+\sigma d \bar{X}(t) \\
d l(t) & =b[\bar{l}-l(t)] d t+\eta d \bar{W}(t)
\end{aligned}
$$

where both $a$ and $b$ are assumed to be positive; $\eta$ is the volatility of $l(t) ; \bar{l}$ is the long-term value of the mean-reversion level, and $\bar{W}(t)$ is assumed to be a second standard Brownian motion uncorrelated with $\bar{X}(t) .{ }^{13}$

I estimated the parameters in both the (29) and (30-31) models using a Kalman-filter-based maximum likelihood procedure. ${ }^{14}$ The basic conclusions of the regression analysis comparing actual swap rates to synthetic generated by the Vasicek-type models confirmed the results obtained with the Ho-Lee

\footnotetext{
${ }^{13}$ The assumption of zero correlation allows me to uniquely interpret $l(t)$ and $a$ as the level and speed of mean reversion of $r(t)$, respectively (Babbs and Nowman, 1999).

${ }^{14}$ Bomfim (2002) provides details of the estimation procedure.
} 
and Hull-White. Although the estimated one-factor Vasicek model had a tendency to underestimate the convexity adjustment relative to the other models, the central result that the futures-implied swap rate and the market swap rate tend to move one-to-one even during the market stress of 1998 was still valid.

\subsection{The Cox, Ingersoll, and Ross Model}

All spot rate models examined so far have the general form

$$
d r(t)=\mu(r, t) d t+v d \bar{X}(t)
$$

where the volatility $v$ of the spot rate $r(t)$ is constant. In addition, these models have the potentially undesirable property of allowing the spot rate to become negative. To examine whether these common characteristics of the models explain why they led me to essentially the same conclusions regarding the importance of counterparty credit risk in the determination of swap rates, I also examined synthetic swap rates derived from the spot rate model developed by Cox, Ingersoll, and Ross (1985). The CIR model assumes that the short rate evolves according to the following real process

$$
d r(t)=a[l-r(t)] d t+\sigma \sqrt{r(t)} d \bar{X}(t)
$$

which is defined under the objective probability measure. (It can be shown that the CIR model rules out negative spot rates.)

Using parameter estimates reported by Gupta and Subrahmanyam (2000), I generated synthetic swap rates based on the CIR model and compared them to market swap rates. Given the parameter values used, the synthetic swap rates implied by the CIR model tended to underestimate the corresponding actual swap rates. Nonetheless, regarding the role of proxies for counterparty credit risk in the determination of swap rates, I generally arrived at 
the same conclusions reached with the other models. In most regressions, counterparty credit risk proxies and the dummy variable for the 1998 crisis had statistically insignificant coefficients attached to them, and even in those cases where the coefficients were significant, they were very small and, most likely, economically insignificant.

\section{Counterparty Risk and Mid-Market Rates}

The analysis in this paper is based on mid-market rates-defined as the average of the bid and offer rates posted by swap dealers - but one might argue that a shortcoming of such an analysis is that it is based on quotes that may be indicative of some "generic" credit quality, rather than on rates at which transactions actually took place. In response to this argument, I would make two points. First, in addition Litzenberger's (1992) work, conversations with dealers themselves suggest that they do not adjust posted rates according to the creditworthiness of counterparties, relying, instead, on credit enhancement mechanisms to manage their exposure to counterparty credit risk. Second, even if the quoted rates were specific to some generic credit quality, the meaning of "generic" could well vary according to the credit environment. For instance, what is considered to be an acceptable risk during "normal" times might be deemed too risky during times of market stress. If that were the case, one would, again, see quoted swap rates deviate from synthetic rates according to the credit environment. I found no evidence of such deviations.

An alternative potential criticism to the analysis would be that adjustments for the credit quality of counterparties are actually made on the bid and offer rates quoted by dealers, and it may well be that these adjustments do not show through in the mid-market rates. For instance, suppose heightened concerns about counterparty credit risk lead dealers to post lower paying rates and higher receiving rates. If such adjustments are always symmetric, 
they would leave mid-market rates unchanged, and a study based on midmarket rates, like this paper, would incorrectly conclude that swap rates are insensitive to concerns about counterparty credit risk.

It turns out, however, that scenarios involving symmetric adjustments to paying and receiving rates in response to concerns about counterparty credit risk require some fairly strong assumptions, especially if the symmetry of adjustments is to be maintained on a day-by-day basis. To see this, recall that what matters to a rational dealer is the likelihood of the joint event of default by her swap counterparty while her position in the swap is in the money. Let us assume at first a flat yield curve. Under such a scenario, the dealer's position in the swap is just as likely to be in as out of the money over some given time horizon and, thus, the dealer needs only care about the credit quality of its counterparty (Sorensen and Bollier, 1994). Given a flat yield curve, what additional assumption would I need to guarantee symmetric adjustments to paying and receiving rates in response to a deterioration in counterparty credit risk? Suppose that the average credit quality of fixed rate payers worsens more than that of fixed rate receivers. In this case, the dealer would increase her receiving rate by more than she would decrease her paying rate, which would lead to a higher mid-market rate. Thus, with a flat yield curve, and maintaining the assumption that, rather than adjusting collateral positions or relying on other credit enhancement mechanisms, the dealer changes her posted swap rates in response to concerns about counterparty credit risk, the mid-market swap rate will be insensitive to such concerns only if the credit quality of her fixed rate payers and receivers always changes to the same degree. Of course a situation that would be consistent with this result would be one where fixed payers and receivers always have the same average credit quality. Nonetheless, such a scenario contradicts some wellknown theories on the rationale for swaps, which suggest that highly rated entities such as AAA-rated firms and government-sponsored enterprises have a tendency to be fixed rate receivers in swaps, while lower quality firms tend 
to be fixed rate payers. ${ }^{15}$ In this case, symmetric adjustments to paying and receiving rates would essentially require that whenever the quality of lower credits deteriorates, that of highly rate entities also worsens to the same degree, an assumption that may not hold in general, especially in a sample as long as the one examined in this paper.

What if I relax the assumption of a flat yield curve? Consider, for instance, an upward sloping yield curve. Intuitively, that would suggest that fixed-paying positions in swaps are now more likely to be in the money in the future and thus the holders of such positions are more likely to be adversely affected by a default by their floating rate payers (fixed rate receivers) (Duffie and Huang, 1996). Other things being equal, dealers would pay a lower fixed rate to offset their greater expected exposure and, by the same logic, would be willing to receive a lower fixed rate. Accordingly, as pointed out by Sorensen and Bollier (1994), in an upward-sloping yield curve environment, the creditworthiness of fixed rate receivers becomes more important in the pricing of swaps than that of fixed rate payers. (The reverse would be true with an inverted yield curve.) As a result, any adjustments that dealers might make in swap rates in a response to changes in counterparty credit risk are generally not symmetric and consequently are likely to leave an imprint on the mid-market swap rates that are examined in this paper. Thus, the fact that I detected no such effect in the empirical analysis of market and synthetic rates suggests that dealers by and large do not adjust their posted rates in response to changes in counterparty credit risk.

\section{Summary and Conclusions}

I used various spot rate models to price the convexity differential between futures and forward contracts. Based on the resulting convexity-adjusted

\footnotetext{
${ }^{15}$ Hull (2000) discusses these theories.
} 
futures rates, as well as the no-arbitrage relationship between par swap rates and the forward LIBOR curve, I constructed a series of synthetic swap rates that can be thought as those that would prevail in a market where swap rates are not adjusted for counterparty credit risk. These synthetic swap rates can then be used as benchmarks against which actual swap ratesthose quoted by dealers - can be compared: Other things being equal, any significant differences between actual and synthetic rates would be indicative of a non-trivial role for counterparty credit risk in the determination of swap rates. The analysis detailed in this paper failed to detect any such differences.

The empirical results are also noteworthy in that this paper is the first to explicitly examine the role of counterparty credit risk in swaps during times of financial market turmoil. I found that the nearly one-to-one relationship between synthetic and market swap rates remained relatively intact even during the 1998 market crisis, which roiled financial markets throughout the world. On the whole, I interpret these findings as confirming empirically the view expressed by some that the netting and credit enhancement mechanisms that are prevalent in the swaps market go a long way in the mitigation of the role of counterparty credit risk in the determination of swap rates.

It should be noted, however, that the finding of no statistically significant role for counterparty credit risk in the determination of market swap rates should not be taken to mean that financial market participants and regulators can simply think of swaps as riskless contracts and ignore the potential for default-related losses in swap books. After all, it is the very existence of working procedures for mitigating counterparty risk that is presumably partly responsible for the lack of sensitivity of swap rates to common proxies for counterparty credit risk. For instance, effective collateralization requires efficient monitoring of risk exposures and the existence of reliable mechanisms for transferring collateral among counterparties. 


\section{Appendix}

\section{A Convexity Adjustment in the Various Mod- els Used in this Paper}

All spot rate models examined in this paper are affine models, i.e., the solution to the bond pricing PDE has the property that zero-coupon bond yields are linear functions of the stochastic variables assumed to influence bond prices $-r(t)$ in the case of the one-factor models, and $r(t)$ and $l(t)$ in the case of the two-factor model. In particular, for the one-factor models,

$$
P(r(t), t, S)=e^{-A(t, S)-B(t, S) r(t)}
$$

where the forms of $A($.$) and B($.$) depend on the specific model being used.$

Equation (34) allows one to write the following general formulae for the simple (discretely compounded) forward rate: ${ }^{16}$

$$
f\left(r(t), t, S_{i-1}, S_{i}\right)=\delta_{i}^{-1}\left[e^{A\left(t, S_{i}\right)-A\left(t, S_{i-1}\right)+\left[B\left(t, S_{i}\right)-B\left(t, S_{i-1}\right)\right] r(t)}-1\right]
$$

For the corresponding futures rates, one can derive the following general formula for the models used in this paper:

$$
F\left(r(t), t, S_{i-1}, S_{i}\right)=\frac{1}{\delta_{i}}\left[e^{A\left(S_{i-1}, S_{i}\right)} \tilde{E}_{t}\left[e^{B\left(S_{i-1}, S_{i}\right) r\left(S_{i-1}\right)}\right]-1\right]
$$

and, thus, the convexity adjustment can be computed as the difference between (36) and (35). ${ }^{17}$

\footnotetext{
${ }^{16}$ Note that for the Ho-Lee and Hull-White models, one can bypass the forward rate formula and use market prices in the right-hand-side of (5). This is because these models are calibrated to exactly fit the yield curve, which implies that the model-implied forward rates will exactly match the ones derived from market prices.

${ }^{17}$ Formulae for the two-factor model are analogously written with the help of matrix
} 
The following is a list of the formulae for $A(t, S), B(t, S)$, and $\tilde{E}_{t}\left[e^{B\left(S_{i-1}, S_{i}\right) r\left(S_{i-1}\right)}\right]$ for every model used in the text.

- Ho-Lee

$$
\begin{aligned}
B(t, S) & =S-t \\
A(t, S) & =\int_{t}^{S} \theta(s)[s-S] d s+\frac{\sigma^{2}[S-t]^{3}}{6} \\
\theta(s) & =\frac{\partial f^{*}(t, s)}{\partial s}+\sigma^{2}[s-t] \\
\tilde{E}_{t}\left[e^{B\left(S_{i-1}, S_{i}\right) r\left(S_{i-1}\right)}\right] & =e^{B\left(S_{i-1}, S_{i}\right) \tilde{E}_{t}\left[r\left(S_{i-1}\right)\right]+\frac{1}{2} \tilde{V}_{t}\left[r\left(S_{i-1}\right)\right] B\left(S_{i-1}, S_{i}\right)^{2}} \\
\tilde{E}_{t}\left[r\left(S_{i-1}\right)\right] & =f^{*}\left(t, S_{i-1}\right)+\frac{\sigma^{2}}{2}\left(S_{i-1}-t\right)^{2} \\
\tilde{V}_{t}\left[r\left(S_{i-1}\right)\right] & =\sigma^{2}\left(S_{i-1}-t\right)
\end{aligned}
$$

where $f^{*}(t, s)$ denotes the instantaneous time-t forward for lending or borrowing at time $s$, for $s>t$, derived directly from observed market prices.

- Hull-White

$$
\begin{aligned}
B(t, S) & =\frac{1-e^{-a(S-t)}}{a} \\
A(t, S) & =\int_{t}^{S}\left[.5 \sigma^{2} B(s, S)^{2}-\theta(s) B(s, S)\right] d s \\
\theta(s) & =-\frac{\partial^{2} \log P^{*}(t, s)}{\partial s^{2}}-a \frac{\partial P^{*}(t, s)}{\partial s}+\tilde{V}_{t}[r(s)]\left(\tilde{E}_{t}\right) \\
\tilde{E}_{t}\left[e^{B\left(S_{i-1}, S_{i}\right) r\left(S_{i-1}\right)}\right] & =e^{B\left(S_{i-1}, S_{i}\right) \tilde{E}_{t}\left[r\left(S_{i-1}\right)\right]+\frac{1}{2} \tilde{V}_{t}\left[r\left(S_{i-1}\right)\right] B\left(S_{i-1}, S_{i}\right)^{2}} \\
\tilde{E}_{t}\left[r\left(S_{i-1}\right)\right] & =f^{*}\left(t, S_{i-1}\right)+\frac{\sigma^{2}}{2} B\left(t, S_{i-1}\right)^{2} \\
\tilde{V}_{t}\left[r\left(S_{i-1}\right)\right] & =\frac{\sigma^{2}}{2 a}\left(1-e^{-2 a\left(S_{i-1}-t\right)}\right)
\end{aligned}
$$

notation. 
where where $P^{*}(t, s)$ denotes observed zero-coupon bond prices.

- One-factor Vasicek

$$
\begin{aligned}
A(t, S) & =\int_{t}^{S} J(s) d s \\
B(t, S) & =\frac{1-e^{-a(S-t)}}{a} \\
\tilde{E}_{t}\left[e^{B\left(S_{i-1}, S_{i}\right) r\left(S_{i-1}\right)}\right] & =e^{B\left(S_{i-1}, S_{i}\right) \tilde{E}_{t}\left[r\left(S_{i-1}\right)\right]+\frac{1}{2} \tilde{V}_{t}\left[r\left(S_{i-1}\right)\right] B\left(S_{i-1}, S_{i}\right)^{2}} \\
\tilde{E}_{t}\left[r\left(S_{i-1}\right)\right] & =e^{-a\left(S_{i-1}-t\right)} r(t)+\left[1-e^{-a\left(S_{i-1}-t\right)}\right] \tilde{l} \\
\tilde{V}_{t}\left[r\left(S_{i-1}\right)\right] & =\frac{\sigma^{2}}{2 a}\left(1-e^{-2 a\left(S_{i-1}-t\right)}\right)
\end{aligned}
$$

where $J(s) \equiv\left(a l-\lambda_{r} \sigma\right) B(t, s)-.5 \sigma^{2} B(t, s)^{2}$ and $\tilde{l} \equiv l-\lambda \sigma / a$.

- CIR

$$
\begin{aligned}
A(t, S) & =-\log \left(\frac{2 \gamma e^{(a+\gamma+\lambda)((S-t) / 2)}}{2 \gamma+(a+\gamma+\lambda)\left(e^{\gamma(S-t)}-1\right)}\right)^{2 a l / v^{2}} \\
B(t, S) & =\frac{2\left(e^{\gamma(S-t)}-1\right)}{2 \gamma+(a+\gamma+\lambda)\left(e^{\gamma(S-t)}-1\right)} \\
\tilde{E}_{t}\left[e^{B\left(S_{i-1}, S_{i}\right) r\left(S_{i-1}\right)}\right] & =\frac{\exp \left(\frac{B\left(S_{i-1}, S_{i}\right) \exp \left(-(a+\lambda)\left(S_{i-1}-t\right)\right) r(t)}{1-B\left(S_{i-1}, S_{i}\right)\left(v^{2} / 2\right) C\left(S_{i-1}\right)}\right)}{\left[1-B\left(S_{i-1}, S_{i}\right)\left(v^{2} / 2\right) C\left(S_{i-1}\right)\right]^{2 a l / v^{2}}} \\
C\left(S_{i-1}\right) & =\frac{1}{a+\lambda}\left(1-e^{-(a+\lambda)\left(S_{i-1}-t\right)}\right)
\end{aligned}
$$

where $\gamma \equiv \sqrt{(a+\lambda)^{2}+2 v^{2}}$.

- Two-factor Vasicek ${ }^{18}$

$$
\begin{aligned}
A(t, S) & =\int_{t}^{S} J(s) d s \\
B(t, S) & =\left(1-e^{-a(S-t)}\right) / a
\end{aligned}
$$

\footnotetext{
${ }^{18}$ For $a=b, C(t, S)$ becomes $\left(1-e^{-a(S-t)}\right) / a-(S-t) e^{-a(S-t)}$.
} 


$$
\begin{aligned}
C(t, S) & =\frac{1}{b}+\frac{e^{-a(S-t)}}{a-b}-a \frac{e^{-b(S-t)}}{b(a-b)} \\
\tilde{E}_{t}\left[e^{A_{Q}\left(S_{i-1}, S_{i}\right) Q\left(S_{i-1}\right)}\right] & =e^{\left.A_{Q}\left(S_{i-1}, S_{i}\right) \tilde{E}_{t}\left[Q\left(S_{i-1}\right)\right]+\frac{1}{2} \tilde{V}_{t}\left[Q\left(S_{i-1}\right)\right] A_{Q}\left(S_{i-1}, S_{i}\right) \tilde{b}_{1}\right)} \\
\tilde{E}_{t}\left[Q\left(S_{i-1}\right)\right] & =e^{-\Xi(s-t)} Q(t)+\left(I-e^{-\Xi(s-t)}\right) \tilde{\Theta} \\
\tilde{V}_{t}\left[Q\left(S_{i-1}\right)\right] & =\int_{t}^{S_{i-1}} e^{-\Xi\left(S_{i-1}-u\right)} \Sigma \Sigma^{\prime} e^{-\Xi^{\prime}\left(S_{i-1}-u\right)} d u
\end{aligned}
$$

where $J(s) \equiv\left(a l-\lambda_{r} \sigma\right) B(t, s)-\lambda_{l} \eta C(t, s)-.5\left(\sigma^{2} B(t, s)^{2}+\eta^{2} C(t, s)^{2}\right)$. $Q(t) \equiv[r(t), x(t)]^{\prime} ; x(t) \equiv l(t)-\hat{l}, \Xi \equiv\left[\begin{array}{ll}a & -a \\ 0 & b\end{array}\right], \Theta \equiv[\bar{l}, 0]^{\prime}, \Sigma \equiv$ $\left[\begin{array}{ll}\sigma & 0 \\ 0 & \eta\end{array}\right], I$ is a $2 \mathrm{x} 2$ identity matrix, $A_{Q}(.) \equiv[B(),. C()$.$] , and \tilde{\Theta} \equiv$ $\Theta-\Xi^{-1}\left[\lambda_{r} \sigma, \lambda_{l} \eta\right]^{\prime}$. 


\section{References}

Babbs, S. and B. Nowman, "Kalman Filtering of Generalized Vasicek Term Structure Models," Journal of Financial and Quantitative Analysis, 1999, 34, 115-30.

Bank for International Settlements, "The global OTC derivatives market at end-December 2001," 2002. Press Release, May 15.

Belton, T., "Credit Risk in Interest Rate Swaps," 1987. Working Paper, Federal Reserve Board.

Bomfim, A., "Monetary Policy and The Yield Curve," 2002. Working Paper, Federal Reserve Board.

Burghardt, G., T. Belton, M. Lane, G. Luce, and R. McVey, Eurodollar Futures and Options: Controlling Money Market Risk, Chicago, IL: Probus, 1991.

Cooper, I. and A. Mello, "The Default Risk on Swaps," The Journal of Finance, 1991, 46, 597-620.

Cox, J., J. Ingersoll, and S. Ross, "The Relation Between Forward Prices and Futures Prices," Journal of Financial Economics, 1981, 9, 321-46.

__ _ _ and __ _ "A Theory of the Terms Structure of Interest Rates," Econometrica, 1985, 53, 385-408.

Duffie, D. and K. Singleton, "An Econometric Model of the Term Structure of Interest Rate Swap Spreads," The Journal of Finance, 1997, 52, $1287-1321$.

and M. Huang, "Swap Rates and Credit Quality," The Journal of Finance, 1996, 51, 921-49. 
Grinblatt, M., "An Analytical Solution for Interest Rate Swap Spreads," International Finance Review, 2001.

and N. Jegadeesh, "Relative Pricing of Eurodollar Futures and Forward Contracts," Journal of Finance, 1996, 51, 1499-1522.

Gupta, A. and M. Subrahmanyam, "An Empirical Examination of the Convexity Bias in the Pricing of Interest Rate Swaps," Journal of Financial Economics, 2000, 55, 239-79.

He, H., "Modeling Term Structures of Swap Spreads," 2000. Working Paper, Yale University.

Ho, T. and S. Lee, "Term Structure Movements and Pricing Interest Rate Contingent Claims," Journal of Finance, 1986, 41, 1011-29.

Huge, B. and D. Lando, "Swap Pricing with Two-Sided Default Risk in a Rating-Based Model," European Finance Review, 1999, 3, 239-68.

Hull, J., Options, Futures, and Other Derivatives, Prentice Hall International Inc., 2000.

and A. White, "Pricing Interest Rate Derivative Securities," Review of Financial Studies, 1990, 3, 573-92.

Kamara, A., "Liquidity, Taxes, and Short-Term Treasury Yields," Journal of Financial and Quantitative Analysis, 1994, 29, 403-17.

Litzenberger, R., "Swaps: Plain and Fanciful," The Journal of Finance, 1992, 42, 831-50.

Liu, J., F. Longstaff, and R. Mandell, "The Market Price of Credit Risk: An Empirical Analysis of Interest Rate Swap Spreads," 2002. NBER Working Paper \#8990. 
Minton, B., "An Empirical Examination of Basic Valuation Models for Plain Vanilla U.S. Interest Rate Swaps," Journal of Financial Economics, 1997, 44, 251-77.

Muelbroek, L., "A Comparison of Forward and Futures Prices of an Interest Rate-Sensitive Financial Asset," Journal of Finance, 1992, 47, 381-96.

Newey, W. and K. West, "A Simple Positive Semi-Definite, Heteroskedasticity and Autocorrelation Consistent Covariance Matrix," Econometrica, 1987, 55, 703-8.

Sorensen, E. and T. Bollier, "Pricing Swap Default Risk," Financial Analysts Journal, May-June 1994, pp. 23-33.

Sun, T., S. Sundaresan, and C. Wang, "Interest Rate Swaps: An Empirical Investigation," Journal of Financial Economics, 1993, 36, 77-99.

Sundaresan, S., "Valuation of Swaps," in S. Khoury, ed., Recent Developments in International Banking and Finance, Vol. 5, New York: Elsevier Science Publishers, 1991.

Vasicek, O., "An Equilibrium Characterization of the Term Structure," Journal of Financial Economics, 1977, 5, 177-88. 
Table 1 - Market and Synthetic Swap Rates ${ }^{a}$

$$
\begin{gathered}
Y^{*}\left(t, S_{n}\right)=\beta_{n, 0}+\beta_{n, 1} \hat{Y}\left(t, S_{n}\right)+e_{n, t} \\
\Delta Y^{*}\left(t, S_{n}\right)=\gamma_{n, 0}+\beta_{n, 1} \Delta \hat{Y}\left(t, S_{n}\right)+u(t, n)
\end{gathered}
$$

\begin{tabular}{lccccc}
\hline \hline & two years & three years & five years & seven years & ten years \\
& & & & & \\
\hline A. Levels & & & & & \\
\hline & 0.0275 & 0.0123 & 0.0662 & 0.0133 & -0.0743 \\
constant & $(0.012)$ & $(0.013)$ & $(0.009)$ & $(0.011)$ & $(0.020)$ \\
& 1.0000 & 1.0006 & 0.9927 & 0.9998 & 1.0194 \\
synthetic rate & $(0.002)$ & $(0.002)$ & $(0.001)$ & $(0.002)$ & $(0.003)$ \\
& & & & & \\
$\bar{R}^{2}$ & 0.9987 & 0.9989 & 0.9992 & 0.9989 & 0.9968 \\
Durbin-Watson & 0.8123 & 1.0551 & 0.9491 & 0.959 & 0.437 \\
$\mathrm{P}\left\{H_{0}: \beta_{n, 1}=1\right\}^{b}$ & 0.99 & 0.70 & 0.00 & 0.90 & 0.00 \\
$\mathrm{P}\left\{H_{0}:\left[\beta_{n, 0}, \beta_{n, 1}\right]=[0,1]\right\}$ & 0.00 & 0.00 & 0.00 & 0.00 & 0.00 \\
& & & & & \\
\hline B. First Differences & & & & & \\
\hline & & & & & \\
constant & -0.0001 & -0.0000 & -0.0000 & -0.0000 & -0.0001 \\
& $(0.001)$ & $(0.001)$ & $(0.001)$ & $(0.001)$ & $(0.001)$ \\
synthetic rate & 0.9255 & 0.9458 & 0.9686 & 0.9674 & 0.9849 \\
& $(0.028)$ & $(0.020)$ & $(0.014)$ & $(0.015)$ & $(0.016)$ \\
$\bar{R}^{2}$ & & & & & \\
Durbin-Watson & 0.9228 & 0.94351 & 0.9594 & 0.9523 & 0.9408 \\
$\mathrm{P}\left\{H_{0}: \beta_{n, 1}=1\right\}$ & 2.9341 & 2.9905 & 2.9610 & 2.8616 & 2.7417 \\
$\mathrm{P}\left\{H_{0}:\left[\gamma_{n, 0}, \beta_{n, 1}\right]=[0,1]\right\}$ & 0.00 & 0.00 & 0.00 & 0.00 & 0.21 \\
& 0.00 & 0.00 & 0.00 & 0.00 & 0.37 \\
\hline \hline
\end{tabular}

${ }^{a}$ Estimation period: January 7, 1994 to March 22, 2002 (428 weekly observations). Heteroskedasticity- and autocorrelation-consistent standard errors shown in parenthesis (Newey and West, 1987).

${ }^{b} P\{$.$\} denote \mathrm{P}$-values associated with null hypothesis shown in brackets. 
Table 2 - Testing for Counterparty Credit Risk ${ }^{a}$

$$
\Delta Y^{*}\left(t, S_{n}\right)=\gamma_{n, 0}+\beta_{n, 1} \Delta \hat{Y}\left(t, S_{n}\right)+\beta_{n, 2} \Delta Y C(t)+v(t, n)
$$

\begin{tabular}{lccccc}
\hline \hline & two years & three years & five years & seven years & ten years \\
\hline \multirow{3}{*}{ constant } & & & & & \\
& -0.0001 & -0.0001 & -0.0001 & -0.0001 & -0.0000 \\
synthetic rate & $(0.001)$ & $(0.001)$ & $(0.001)$ & $(0.001)$ & $(0.001)$ \\
& 0.9252 & 0.9472 & 0.9705 & 0.9690 & 0.9856 \\
BBB/AAA spread & $(0.028)$ & $(0.020)$ & $(0.014)$ & $(0.015)$ & $(0.015)$ \\
& -0.0040 & 0.0226 & 0.0331 & 0.0264 & 0.0121 \\
& $(0.039)$ & $(0.033)$ & $(0.028)$ & $(0.028)$ & $(0.028)$ \\
$\bar{R}^{2}$ & & & & & \\
Durbin-Watson & 0.9226 & 0.9434 & 0.9594 & 0.9522 & 0.9407 \\
& 2.9339 & 2.9914 & 2.9613 & 2.8584 & 2.7403 \\
\hline \hline
\end{tabular}

${ }^{a}$ Estimation period: January 7, 1994 to March 22, 2002 (428 weekly observations). Heteroskedasticity- and autocorrelation-consistent standard errors shown in parenthesis (Newey and West, 1987). 
Table 3 - Swap Valuation during the 1998 Market Crisis $^{a}$

\begin{tabular}{|c|c|c|c|c|c|}
\hline & two years & three years & five years & seven years & ten years \\
\hline \multicolumn{6}{|c|}{ A. $\Delta Y^{*}\left(t, S_{n}\right)=\gamma_{n, 0}+\beta_{n, 1} \Delta \hat{Y}\left(t, S_{n}\right)+\beta_{n, 2} \phi(t)+v(t, n)$} \\
\hline constant & $\begin{array}{c}-0.0001 \\
(0.001)\end{array}$ & $\begin{array}{c}-0.0001 \\
(0.001)\end{array}$ & $\begin{array}{c}-0.0001 \\
(0.001)\end{array}$ & $\begin{array}{c}-0.0001 \\
(0.001)\end{array}$ & $\begin{array}{c}0.0001 \\
(0.001)\end{array}$ \\
\hline \multirow[t]{2}{*}{ synthetic rate } & 0.9249 & 0.9456 & 0.9685 & 0.9670 & 0.9845 \\
\hline & $(0.028)$ & $(0.021)$ & $(0.014)$ & $(0.015)$ & $(0.015)$ \\
\hline \multirow[t]{2}{*}{ dummy $(\phi(t))$} & -0.0031 & -0.0013 & -0.0003 & -0.0037 & -0.0049 \\
\hline & $(0.009)$ & $(0.010)$ & $(0.007)$ & $(0.007)$ & $(0.007)$ \\
\hline $\bar{R}^{2}$ & 0.9226 & 0.9434 & 0.9593 & 0.9522 & 0.9407 \\
\hline Durbin-Watson & 2.9334 & 2.9905 & 2.9610 & 2.8628 & 2.7421 \\
\hline \multicolumn{6}{|c|}{ B. $\Delta Y^{*}\left(t, S_{n}\right)=\gamma_{n, 0}+\beta_{n, 1} \Delta \hat{Y}\left(t, S_{n}\right)+\left[\beta_{n, 2}+\beta_{n, 3} \phi(t)\right] \Delta Y C(t)+v(t, n)$} \\
\hline \multirow[t]{2}{*}{ constant } & -0.0001 & -0.0001 & -0.0002 & -0.0001 & -0.0001 \\
\hline & $(0.001)$ & $(0.001)$ & $(0.001)$ & $(0.001)$ & $(0.010)$ \\
\hline \multirow[t]{2}{*}{ synthetic rate } & 0.9252 & 0.9471 & 0.9703 & 0.9689 & 0.9856 \\
\hline & $(0.028)$ & $(0.020)$ & $(0.014)$ & $(0.015)$ & $(0.015)$ \\
\hline \multirow[t]{2}{*}{$\mathrm{BBB} / \mathrm{AAA}$ spread } & -0.0072 & 0.0129 & 0.0186 & 0.0220 & 0.0093 \\
\hline & $(0.050)$ & $(0.039)$ & $(0.034)$ & $(0.035)$ & $(0.035)$ \\
\hline \multirow[t]{2}{*}{ dummy $(\phi(t) \Delta Y C(t))$} & 0.0089 & 0.0279 & 0.0414 & 0.0127 & 0.0080 \\
\hline & $(0.081)$ & $(0.074)$ & $(0.062)$ & $(0.060)$ & $(0.059)$ \\
\hline $\bar{R}^{2}$ & 0.9224 & 0.9433 & 0.9593 & 0.9521 & 0.9406 \\
\hline Durbin-Watson & 2.9345 & 2.9940 & 2.9661 & 2.8598 & 2.7409 \\
\hline
\end{tabular}

${ }^{a}$ Estimation period: January 7, 1994 to March 22, 2002 (428 weekly observations). Heteroskedasticity- and autocorrelation-consistent standard errors shown in parenthesis (Newey and West, 1987). 
Figure 1

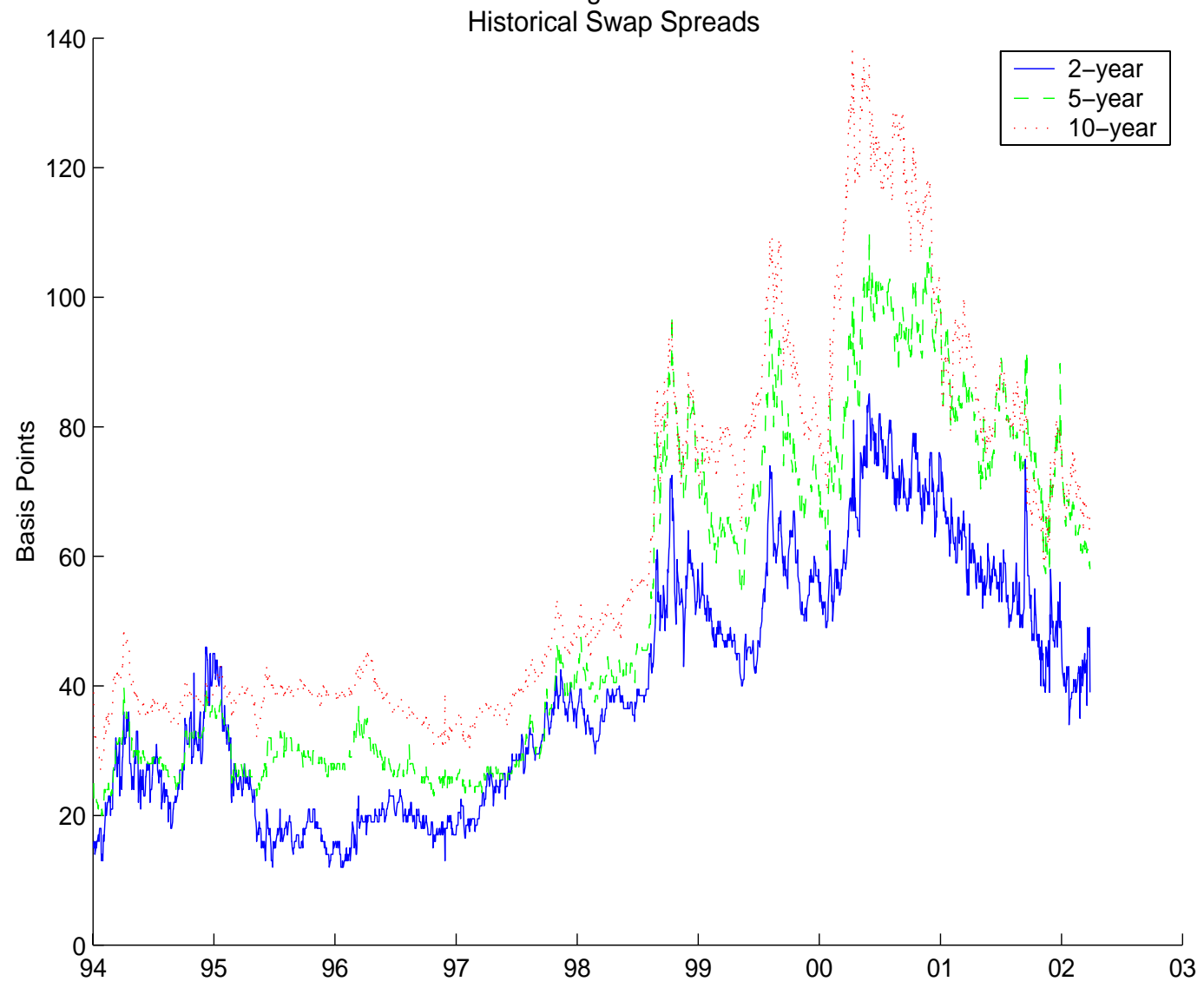

* The figure shows spreads of two-, five-, and ten-year swap rates over yields on U.S. Treasury debt securities of comparable maturities. 
Figure 2

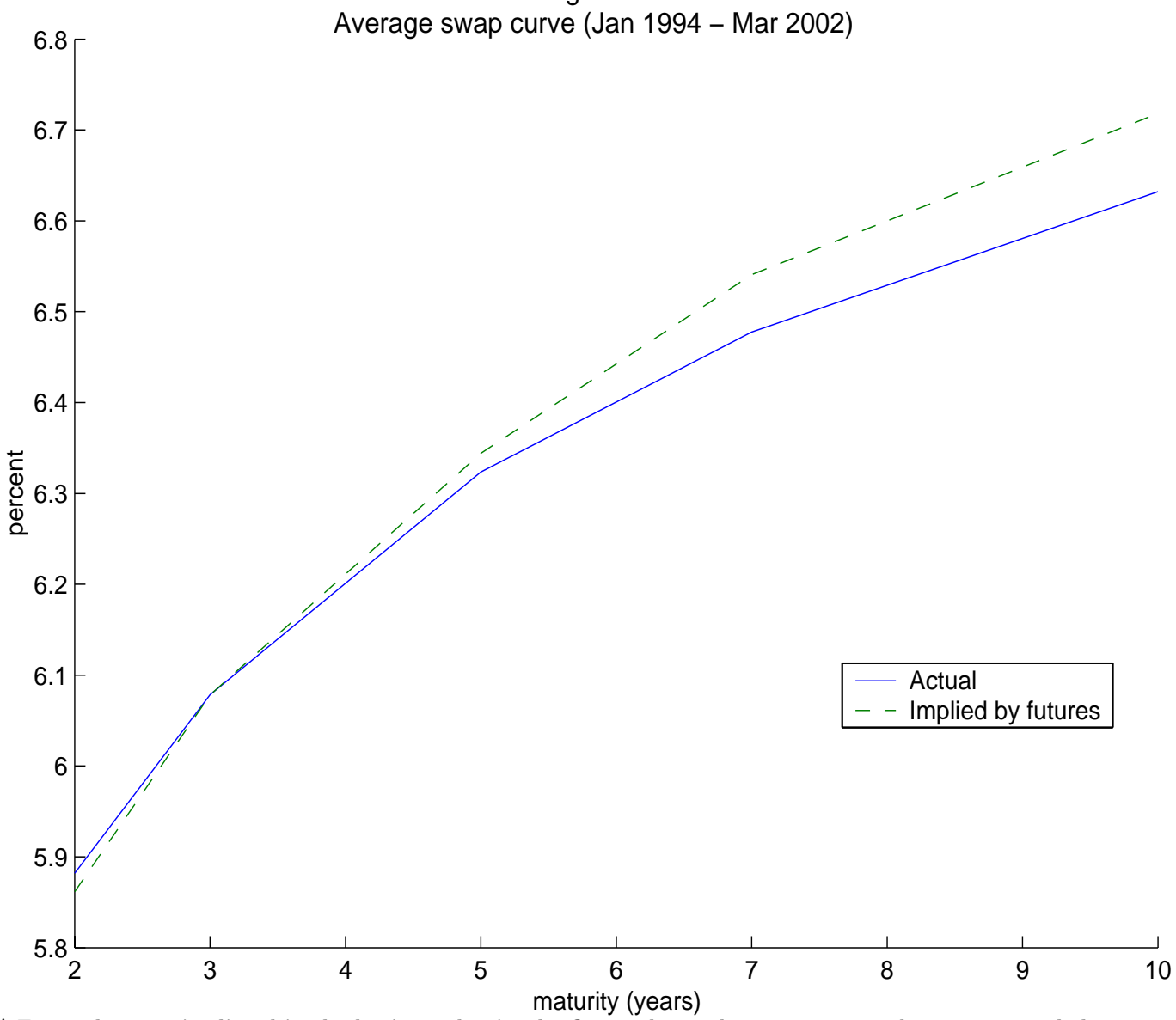

* For each maturity listed in the horizontal axis, the figure shows the average actual swap rate and the average futures-implied swap rate over the entire January 1994-March 2002 sample. The underlying data are composed of weekly observations. 
Figure 3

Actual and Theoretical Swaption Prices*
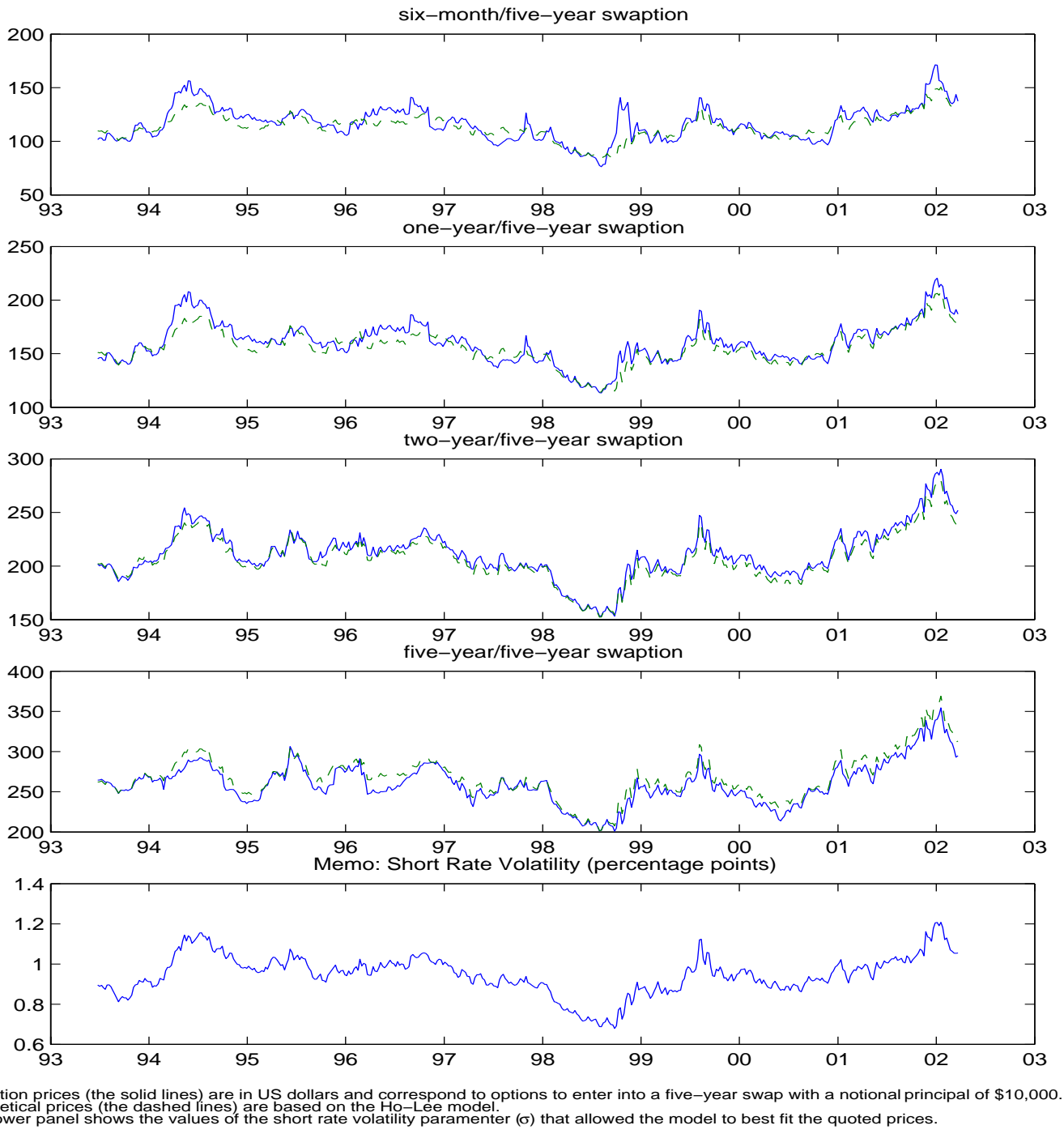
Figure 4

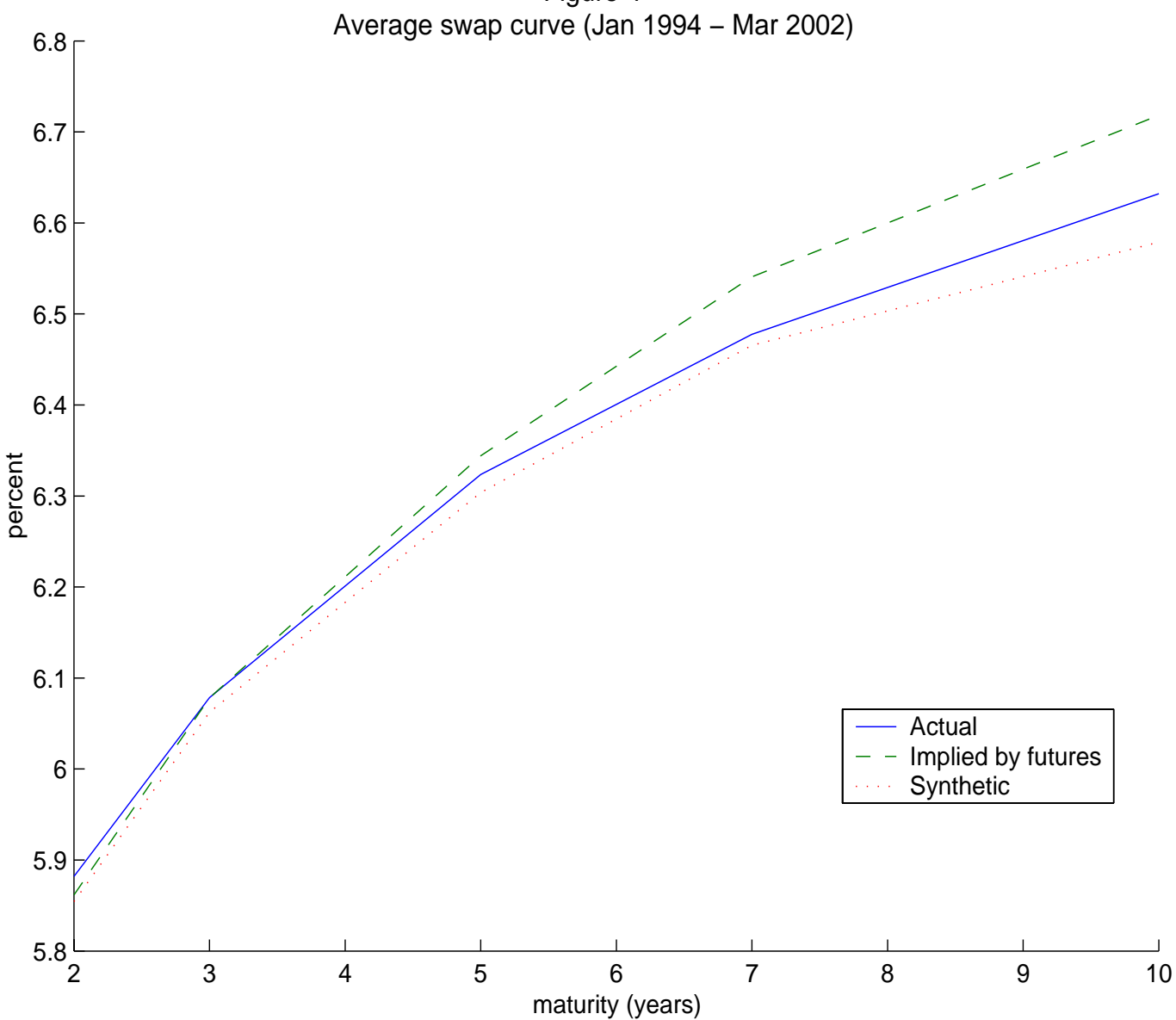

* For each maturity listed in the horizontal axis, the figure shows the average actual swap rate, the average futures-implied swap rate, and the average synthetic swap rate over the entire January 1994-March 2002 sample. (The solid and dashed curves are the same ones shown in Figure 2.) The underlying data are composed of weekly observations. 
Figure 5

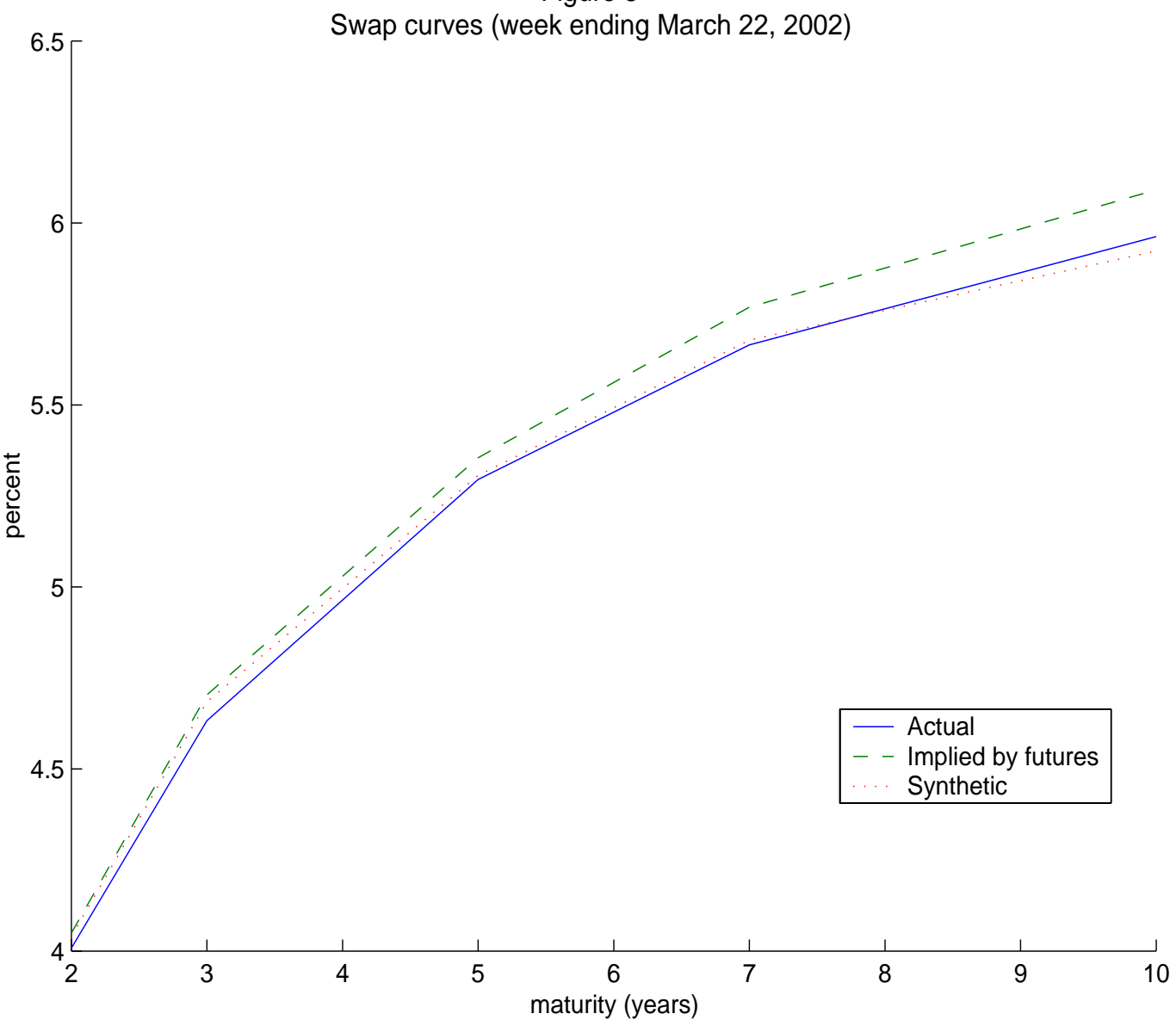

* The figure shows the actual swap curve, the futures-implied swap curve, and the synthetic swap curve on the week ending March 22, 2002. (Figures 2 and 4 showed average rates over the 1994/2002 sample, which included this particular week.) 
Figure 6: Spread between Actual and Synthetic Swap Rates

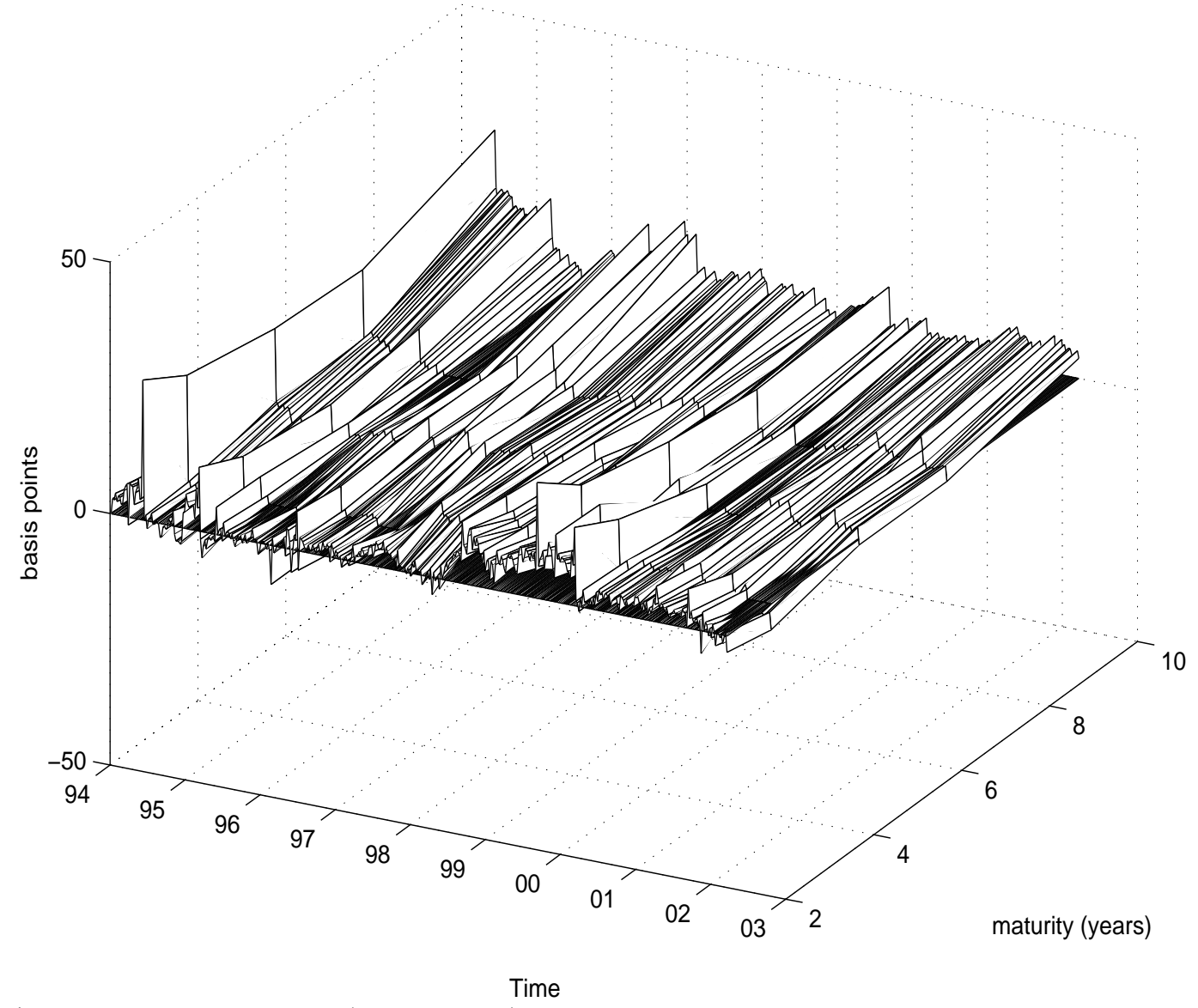

* The figure shows differences (in basis points) between actual and synthetic swap rates over time and

across various maturities. 
Figure 7

Residuals of Levels Regressions
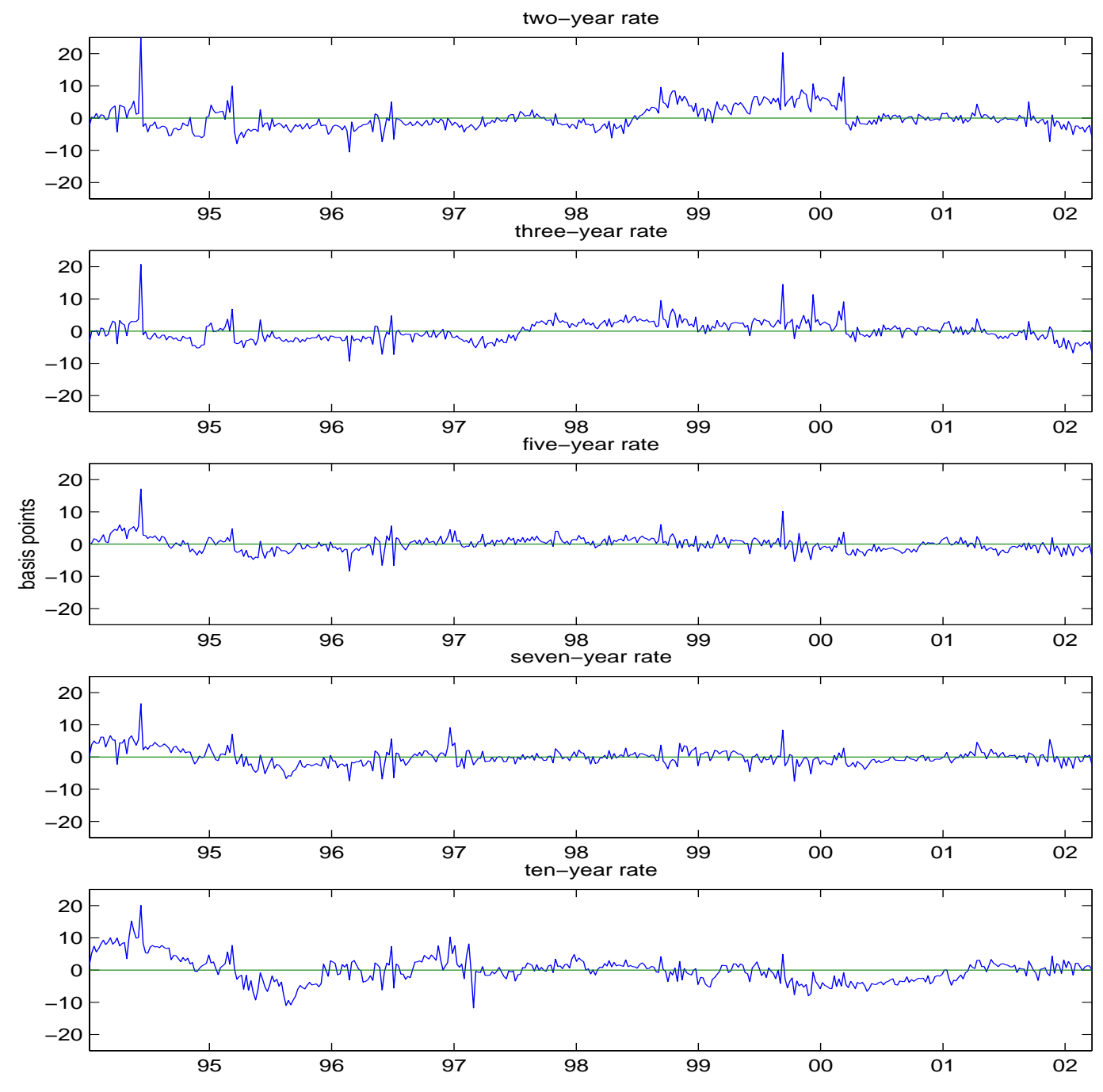

* The figure shows the residuals from regressing market swap rates with the maturity indicated in each panel on a constant and on the corresponding synthetic swap rate. 
Figure 8

Residuals of First-Differences Regressions
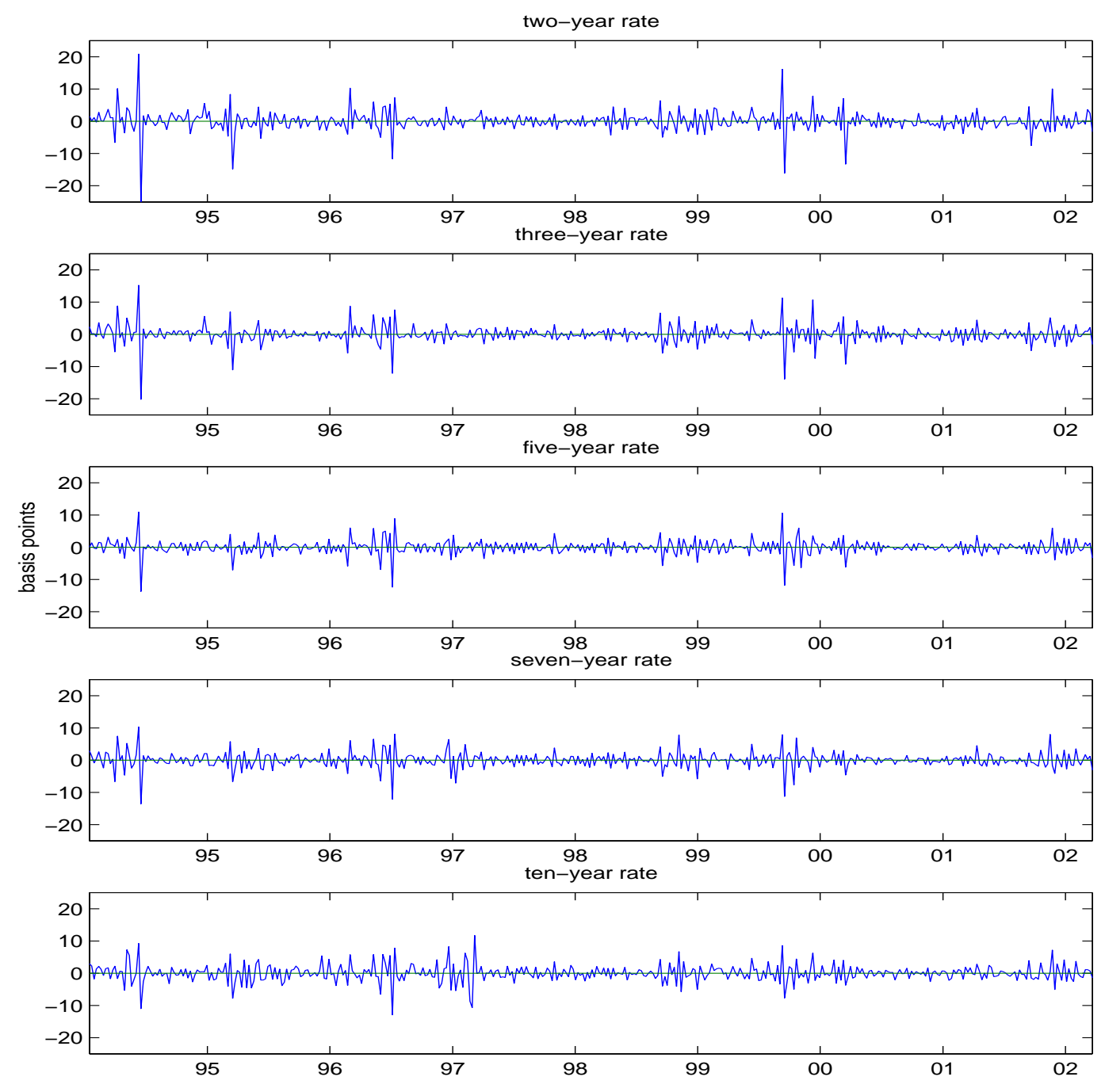

* The figure shows the residuals from regressing changes in market swap rates with the maturity indicated in each panel on a constant and on changes in the corresponding synthetic swap rate. 